\title{
Exploring the Relationship Between Education and Obesity
}

\author{
by
}

Marion Devaux, Franco Sassi, Jody Church, Michele Cecchini and Francesca Borgonovi*

An epidemic of obesity has been developing in virtually all OECD countries over the last 30 years. Existing evidence provides a strong suggestion that such an epidemic has affected certain social groups more than others. In particular, a better education appears to be associated with a lower likelihood of obesity, especially among women. This paper sheds light on the nature and the strength of the correlation between education and obesity. Analyses of health survey data from Australia, Canada, England, and Korea were undertaken with the aim of exploring this relationship. Social gradients in obesity were assessed across the entire education spectrum, overall and in different population sub-groups. Furthermore, investigations testing for mediation effects and for the causal nature of the links observed were undertaken to better understand the underlying mechanisms of the relationship between education and obesity.

JEL classification: I12, I21

Keywords: obesity, education, social disparities, mediation effect

\footnotetext{
* Marion Devaux (marion.devaux@oecd.org), Franco Sassi (franco.sassi@oecd.org) and Michele Cecchini (michele.cecchini@oecd.org) all work in the Health Division of the OECD Directorate for Employment, Labour and Social Affairs, Francesca Borgonovi (francesca.borgonovi@oecd.org) works in the Indicators and Analysis Division of the OECD Directorate for Education and Jody Church (Jody.Church@uts.edu.au) is at the Centre for Health Economics Research and Evaluation, University of Technology in Sydney, Australia. The views expressed are those of the authors and should not be interpreted as representing those of the OECD or its member governments.
} 
O verweight and obesity rates have been increasing sharply over recent decades in all industrialised countries, as well as in many lower-income countries. The rise in obesity has reached epidemic proportions, with over 1 billion adults worldwide estimated to be overweight and at least 300 million of those considered to be clinically obese (WHO, 2003). The circumstances in which people have been leading their lives over the past 20-30 years, including physical, social and economic environments, have exerted powerful influences on their overall calorie intake, on the composition of their diets and on the frequency and intensity of physical activity at work, at home and during leisure time. On the other hand, changing individual attitudes, reflecting the long-term influences of improved education and socio-economic status (SES) have countered to some extent environmental influences.

Many OECD countries have been concerned not only about the pace of the increase in overweight and obesity, but also about inequalities in their distribution across social groups, particularly by level of education, socio-economic status and ethnic background. Inequalities across social groups appear to be particularly large in women (Wardle et al., 2002; Branca et al., 2007). Acting on the mechanisms that make individuals who are poorly educated and in disadvantaged socio-economic circumstances so vulnerable to obesity, and those at the other end of the socio-economic spectrum much more able to handle obesogenic environments, is of great importance not just as a way of redressing existing inequalities, but also because of its potential effect on overall social welfare. The current distribution of obesity appears particularly undesirable, as it is likely to perpetuate the vicious circle linking obesity and disadvantage by intergenerational transmission.

Research has produced ample evidence of the individual labour market returns of education. Economists have shown much interest in the estimation of the causal effect of education on wages and economic growth (see Card 2001, for a comprehensive review of the literature) but only recently has work begun to investigate the non-monetary returns of schooling (see McMahon, 2004 for a review). Empirical studies, for example, suggest that education has a positive impact on health and well-being (Wolfe and Haveman 2002; LlerasMuney 2005), particularly in poorer countries (Cutler and Lleras-Muney, 2006), reduces crime (Lochner and Moretti 2004) and water and air pollution (Appiah and McMahon 2002). The finding that education has positive externalities provides a rationale for government intervention.

However, the causal nature of the link between education and health is still subject to a certain degree of scrutiny, and the precise mechanisms through which education may affect health are not yet fully understood. Lifestyles may be one of the keys to understanding such a relationship, as they are often significantly influenced by education and, at the same time, they contribute to health and longevity by affecting the probability of developing a wide range of diseases. Obesity is a close marker of important aspects of individual lifestyles, such as diet and physical activity, and is also an important risk factor for major chronic diseases, such as diabetes, heart disease, stroke and certain cancers. Obesity is also associated with negative labour market outcomes, in term of both wages and employment, particularly for women (Cawley, 2004; Brunello et al., 2006). 
The aim of this paper is to provide new evidence concerning the relationship between education and obesity and contribute to understand the nature of such relationship and its implications for health and education policy. The empirical analyses on education and obesity undertaken by the OECD focus on four countries: Australia, Canada, England and Korea. Data from health surveys regularly undertaken in the four countries were used in a range of analyses, in pursuit of the following specific objectives:

1. To explore the correlation between body mass index, and obesity, on one hand, and formal education, expressed in terms of years spent in full-time education, on the other, controlling for possible confounding factors. The main goal of this analysis is to determine whether the intensity of the relationship between education and obesity is constant, or whether it shows increasing or decreasing strength at either end of the education spectrum.

2. To assess the extent to which the correlations identified may reflect the influences of factors associated with individual education, such as socio-economic status and the level of education of household members.

3. To assess the extent to which the correlations identified may reflect causal links between education and obesity.

4. To explore what conceptual model of the role of education as a determinant of health is most consistently supported by the findings concerning the correlation between obesity and aspects of individual and group education.

\section{Box 1. Data description}

The analyses reported in this paper are based on individual-level national health surveys covering four OECD countries: Australia, Canada, England and Korea. Data sources include the Australian National Health Survey (NHS) 1989-2005, the Canadian National Population Health Survey-cross-section (NPHS) and the Canadian Community Health Survey (CCHS) 1995-2005, the Health Survey for England (HSE) 1991-2005 and the Korean National Health and Nutrition Examination Survey (KNHANES) 1998-2005. All available survey waves were pooled for each survey. Since the focus of the analyses was the relationship between obesity and education, survey samples were restricted to individuals in the age range 25-64 who were supposed to have completed their full time education, and for whom the body mass index is a useful proxy for health risk. Body mass index (BMI) was calculated as weight in kilograms divided by square height in meters. Obesity and overweight status were then derived as BMI greater than 30 and 25.

The analyses were conducted by applying the same models to all countries' data, in order to facilitate comparisons across countries. However, differences in data and survey methods sometimes make it difficult to achieve complete consistency. For instance, data on height and weight were measured by examination in England and Korea while they were self-reported in the other two countries. The education variable was obviously a critical one, and the format of this variable varied across countries. We created a variable reflecting the numbers of years spent by each individual in full-time education using all the information available in each dataset on years of schooling and educational attainment. For consistency, we grouped together individuals with no education and those with the lowest level of education, as these two groups were not always separated in the available datasets. A certain degree of heterogeneity was also present in relation to the socio-economic status (SES) variable, as occupation-based social class was reported in the English data, while equivalised household income was available in Australia, Canada and Korea. Individuals were allocated to income quintiles in Australia and Korea, and to income groups based on fixed income ranges in Canada. Finally, an ethnicity variable was available in England, while proxies were used in Canada (minority status) and Australia (migrant status). No such variable was available in Korea. Tables of descriptive statistics are presented in Annex A1. 


\section{Existing evidence on the relationship between education and obesity}

The existing evidence concerning the relationship between education and obesity is relatively limited, as the main focus of most research has been more broadly on the links between socio-economic factors and health status, or longevity, with a smaller number of studies focusing on lifestyles and on obesity in particular. The evidence available, covering a number of OECD countries, generally shows strong associations between education and obesity. However, there have been only few studies that have investigated the causal effects of education on obesity, and these studies have reported mixed results.

Cutler and Lleras-Muney (2006) found that those with more years of schooling are less likely to smoke, drink a lot, to be overweight or obese or to use illegal drugs. Similarly, the better educated are more likely to exercise and to obtain preventive care such as flu shots, vaccines, mammograms, pap smears and colonoscopies. They also found the relationship between education and health appears to be non-linear for obesity, with increasing effects of additional years of schooling. A review by Grossman and Kaestner concluded that years of formal schooling is the most important correlate of good health (Grossman et al., 1997). Cross-sectional estimates from a study of twins conducted by Webbink et al. (2008), also confirms the negative relationship between education and the probability of being overweight. By looking at differences between the sexes within a study of socio-economic factors and obesity, Yoon et al. (2006) found that income, rather than education, had a greater effect on BMI and waist circumference in men, whereas higher levels of education for women resulted in lower BMI and waist circumference.

The correlation between education and health may reflect three possible types of relationships: a) a causal link running from increased education to improved health, b) a reverse causal link, indicating that better health leads to greater education; or c) an absence of a causal relationship between education and health, which appear to be correlated because of possible unobserved factors affecting both health (or obesity) and education in the same direction. The three pathways are not mutually exclusive, of course, and some combination of the three is likely to provide the most plausible explanation of the strong correlations consistently found across countries between education and health, or obesity. Cutler and Lleras-Muney (2006) argue that children in poor health obtain less schooling and because of this they are also more likely to be unhealthy adults. Similarly, evidence on longitudinal data shows that becoming overweight during the first four years in school is a significant risk factor for adverse school outcomes in girls (Datar and Sturm, 2006). Unobserved factors possibly contributing to the third pathway identified may include family background, genetic traits or other individual differences, such as ability to delay gratification. These factors may explain why the more educated are also healthier. Cutler and Lleras-Muney (2006) found that even controlling for some of these factors, the effect of education on health generally remains large and significant. Although there is evidence to support the hypothesis that the direction of causality is from more schooling to better health (Grossman, 2000), when overall health status or longevity are the outcomes of interest, there are few studies shedding light on the causal nature of the relationship between education and obesity specifically. Results from Lundborg (2008) suggest that a causal effect of education on health exists, but found no evidence that lifestyle factors such as smoking and obesity contribute to the health/education gradient. Natural experiments where policy changes are implemented that directly affect the number of years of mandatory schooling, can provide an indication of the causal nature of the link between education and obesity. Arendt (2005) used changes in compulsory education laws in 
Denmark and found inconclusive results regarding the effect of education on BMI. However, Spasojevic, (2003) using a similar estimation strategy for Sweden found that additional years of education have a causal effect on maintaining a healthy body mass index. Clark and Royer (2008) focused on an educational reform implemented in England in 1947, which increased the minimum compulsory schooling age in the country, from 14 to 15 . They found that cohorts affected by the law display only slightly improved long-run health outcomes and their findings did not support a causal link between education and obesity. Brunello et al. (2009) used compulsory school reforms implemented in European countries after the Second World War to investigate the causal effect of education on the BMI and the incidence of overweight and obesity among European females. They showed that years of schooling have a protective effect on BMI. On US data, Grabner (2009) used the variation caused by state-specific compulsory schooling laws between 1914 and 1978 as an instrument for education, and found a strong and statistically-significant negative effect of additional schooling on BMI, effect especially pronounced in females.

Michael Grossman's demand for a health model, developed in the 1980s, hypothesised that "schooling raises a person's knowledge about the production relationship and therefore increases his or her ability to select a healthy diet, avoid unhealthy habits and make efficient use of medical care" (Kemna, 1987). Educated individuals make better use of health-related information than those who are less educated. Education provides individuals with better access to information and improved critical thinking skills. Speakman et al. (2005) hypothesised that the lack of education about energy content of food may contribute to the effects of social class on obesity. Results from their study show that on average, non-obese individuals in the lower social class group have better food knowledge than those who are obese in the same group. However non-obese subjects in all groups overestimate food energy in alcoholic beverages and snack foods indicating poorer knowledge of the energy content of these foods. Lack of information could also affect one's own perception of their body mass. Research has shown that over time more overweight individuals are under-perceiving their body mass compared with people with normal weight (Haas, 2008). It is possible that more highly-educated people have the knowledge to develop healthy lifestyles and have more awareness of the health risks associated with being obese (Yoon, 2006). The more educated are more likely to choose healthy lifestyles; however, it has been shown that the highly educated choose healthier behaviours than individuals who are highly knowledgeable about the consequences of those behaviours (Kenkel, 1991). This could indicate that the effect of education on obesity is driven by different mechanisms, and not just by information and knowledge about healthy lifestyles.

Exploring the link between education and obesity is important, as this may lead to the development of appropriate education-based policies to counteract recent trends in obesity and related chronic diseases. For example, if the findings reported by Cutler and Lleras-Muney (2006) showing increased effects of additional years of schooling for those who are better educated were confirmed by further analyses, these would provide support for education policies aimed at promoting higher education, as these would produce greater health returns.

\section{Policy and institutional environment}

Policies aimed at counteracting the negative effects of obesity through the education system can be of two main types: policies focusing on the educational environment, aimed 
at promoting healthier lifestyles by exposing children to healthier environments and by providing health education; and policies aimed at encouraging higher levels of general education. Although the relationship between years of schooling, or educational attainment, and health outcomes is well established, most of the policies encountered to improve health by promoting lifestyle changes have focused on educating the population about healthier lifestyles as opposed to providing more general education. Each of the four countries examined in this study have implemented policies to strengthen "healthy living" education within schools, with the aim of achieving better health outcomes.

Australia has developed National Goals for Schooling in the Twenty-First Century, to which authorities across governmental jurisdictions refer to provide young Australians with the best possible educational outcomes and improve the quality of schooling nationally. The Active School Curriculum/ Building a Healthy Active Australia through the Department of Health and Ageing aims to provide young people with the skills to embrace an active lifestyle by introducing them to a range of physical activities. All state and territory governments and non-government education authorities have committed to providing in their curriculum at least two hours of physical activity each school week for primary and junior secondary school children under the Schools Assistance Act 2004. Also, the Australian Social Inclusion Agenda of the Australian Labour Party recommended that more young people from disadvantaged backgrounds complete 12 years of schooling and go on to further education and training.

In Canada, due to the vast geographical dispersion of the population, many policies relating to health and education are conducted at the provincial/territorial level. Nova Scotia, for example, implemented the Annapolis Valley Health Promoting Schools programme in seven elementary schools, with preliminary results indicating that those schools which implemented the programme had significantly lower rates of overweight and obese students. The British Columbia Children's Hospital and the University of British Columbia implemented a programme called "Healthy Buddies" to empower elementary school children to live healthier lives by providing them with knowledge about health and physical activity. Results from the programme have shown that students had an increase in their healthy-living knowledge and BMI and less weight gain than students who were not in the programme. In Quebec the "Take care of your health!" programme delivered by ACTI-MENU (a health promotion organisation) aimed to provide employees with information and support risk factor reduction. Evaluation of the programme revealed that participants were more likely to report more frequent physical activity and better nutritional practices and absenteeism declined by $28 \%$ and turnover by $54 \%$.

As part of the National Health Promotion Act, Korea established national policies aimed at enhancing people's health through health education, disease prevention, nutrition improvement and the practice of healthy lifestyles. The Health Plan 2010 aims at improving the nutritional status of the population and a part of this was the revision and dissemination of dietary guidelines, enforcing mandatory nutrition labelling and providing information to groups deemed vulnerable such as the elderly and young children. Part of this strategy is to develop the plan in line with educational, political, economic and organisational means. The Health Plan 2010 includes activities focusing on the development of nutritious diets, development of obesity prevention and management programmes and physical activity campaigns. 
"Healthy Weight, Healthy Lives: A Cross-Government Strategy for England" is a project which targets children for healthy growth and healthy weight. Funded through the Department of Health, this strategy aims to reduce the proportion of overweight and obese children back to the levels found in 2000 by 2020. The NHS (National Health Service) has strategies aimed at offering public advice and support to those who already have weight problems through weight management programmes, NHS websites, as well as by developing the ability of health-service staff to deal with issues of excess weight. Additionally, strategies exist in England to combat obesity through the promotion of healthier food choices, by limiting food advertising to children and working with the food industry to reduce salt, sugar and fat in foods; as well as strategies such as "Walking into Health" to build physical activity into the lives of the whole population and "Active England" aimed at promoting non-sport physical activity.

\section{General trends in obesity in the four countries}

The distribution of BMI in the four countries concerned has been shifting in a characteristic fashion over the past few decades, as illustrated in Sassi et al., 2009. In particular, as in most OECD countries, a sizable share of the normal weight population has been progressively gaining weight, moving towards the pre-obese category first, then progressively towards obesity and, in some cases, morbid obesity (BMI $>40$ ). A visible increase in the percentage of the population that is obese was recorded for both men and women, across all four countries (Figure 1). However, a significant difference in trends between genders is observed in Korea, where the relative distribution of females over the BMI categories remained relatively stable between 1998 and 2005, while a 10\% decrease in the normal weight category was observed in men, followed by a $9 \%$ increase in the preobese category and a $2 \%$ increase in the obese category. On the other hand, in 2005 Korea had only $4 \%$ of its population obese, on average, compared with $25 \%$ in England, $18 \%$ in Australia and $17 \%$ in Canada. In the latter three countries the percentage of overweight men is significantly higher than that of women. In Canada, the majority of men were overweight in all survey years, and the same has been true in England since 1995.

Figure 1. Trends in age-standardised obesity rates in Australia, Canada, England and Korea
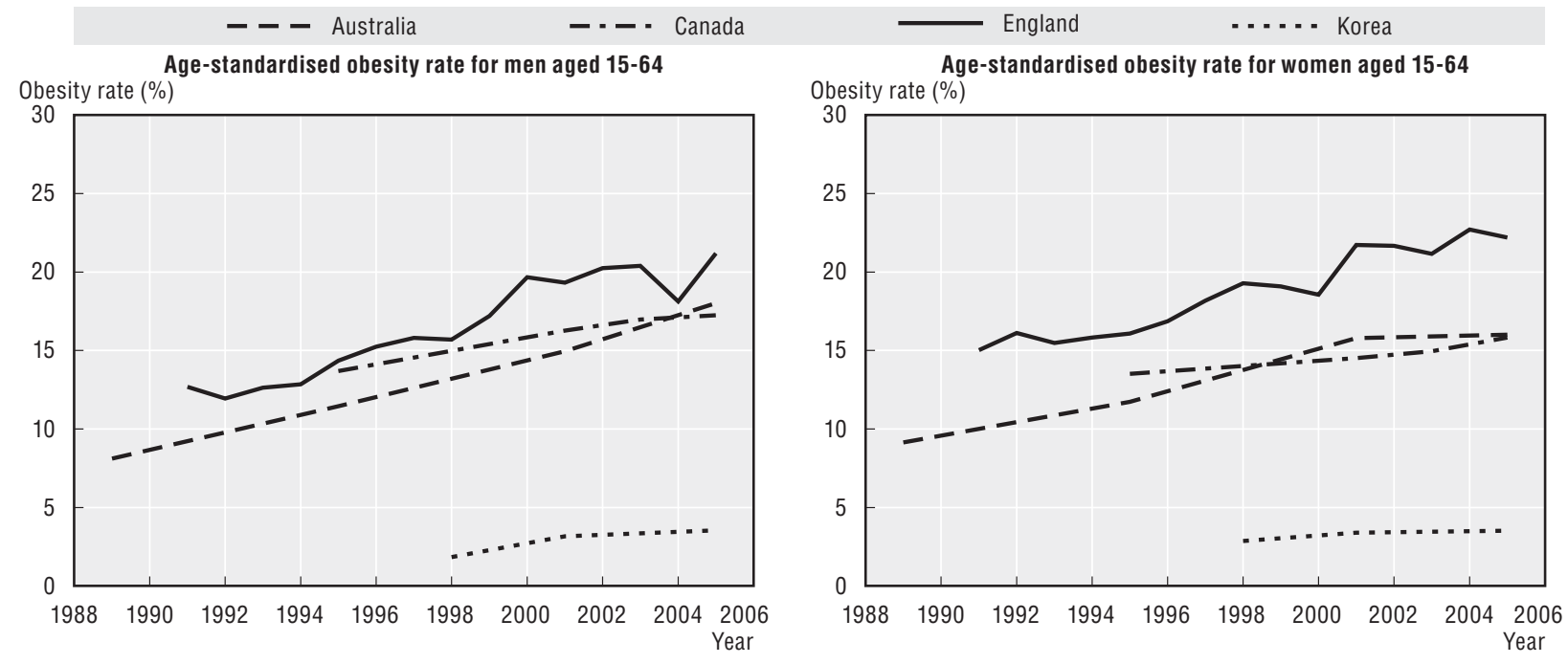

Source: Authors' estimates using 2005 OECD standard population. 


\section{Box 2. Methods}

Differences in obesity rates among population groups with different levels of education were first analysed using logistic regression models controlling for a range of covariates, including gender, age, ethnicity, socioeconomic status and survey year (Figure 2 and Annex A2). An interaction term between education and gender was also included in the regression model for the purpose of assessing differences between the two genders in the relationship between education and obesity (Figures 4 to 6, and Annex A3). The relationship between education and obesity in different ethnic groups was similarly explored through an interaction term between years of education and ethnicity (minority status in Canada, migrant status in Australia). The relationship between BMI and education was analysed using ordinary least squares regression models including the same covariates listed above (Figure 3 and Annex A2). All analyses were conducted using Stata 10.

Obesity rates, as well as BMI levels, by years of education were reported in separate graphs for different population groups. The linearity of the relationship between education and obesity and BMI was assessed visually, based on those graphs.

The effects of the clustering of individuals into households or geographical areas were studied using multilevel statistical models, also known as hierarchical linear models, random effects models or nested models (see Annex A4). Multilevel analyses concerned England and Korea, data which are based on household structure. Two-level random-intercept models, using households as higher-level units of aggregation, were tested on samples of people aged 25-64, living in a household comprising at least two members. It was not possible to perform this analysis on Australian and Canadian data, since the relevant surveys do not have a household structure.

\section{Is the strength of the correlation between education and obesity constant across the entire education spectrum, overall and in different population sub-groups?}

Figure 2 shows the relationship between education and obesity for each gender in the four countries. Obesity rates in Figure 2 and BMI levels in Figure 3 are regression estimates adjusted for age, gender, and socio-economic status. Full results are presented in Annex A2. The relationship is negatively sloped in all cases except in Korean men, indicating that each additional year of education is consistently associated with a lower chance of being obese in Australia, Canada and England, as well as in Korean women. For Korean men, no conclusive results could be obtained as none of the coefficients for education were significant in the regression analysis, possibly due to the relatively small number of individuals who are obese in the country.

The patterns shown in Figure 2 suggest that the relationship between obesity and years of education may be considered broadly linear, i.e. of a constant strength across the entire education spectrum. However, results for England and Canada might suggest that the effect of further years of education tends to decrease progressively when approaching completion of upper secondary education (13-14 years of schooling), and then increase again sharply in individuals who complete tertiary education. A similar effect was also found for men in Australia, based on 2001 and 2005 data, which provided more detailed information on years of education relative to other editions of the same survey.

When the relationship between average BMI and education is observed, as in Figure 3, the conclusions are similar to what was previously discussed. No clear and consistent deviation is observed from a linear pattern in the four countries examined. Again Korean men represent an exception, as they display a positively sloped relationship, which seems substantially more marked than in Figure 2, where the link between education and obesity was examined. 
Figure 2. Relationship between obesity and years of education
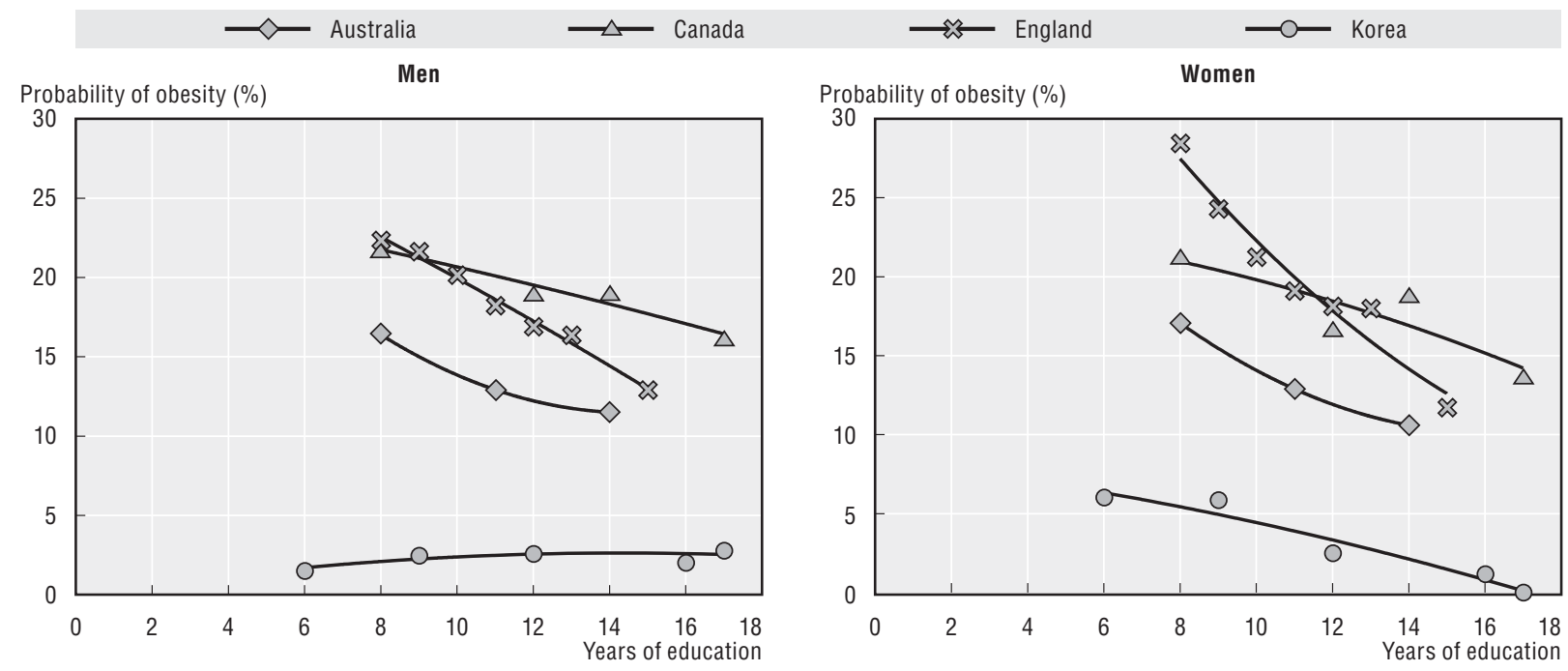

Source: Authors' estimates from logistic regression, see Annex A2.

Figure 3. Relationship between BMI and years of education
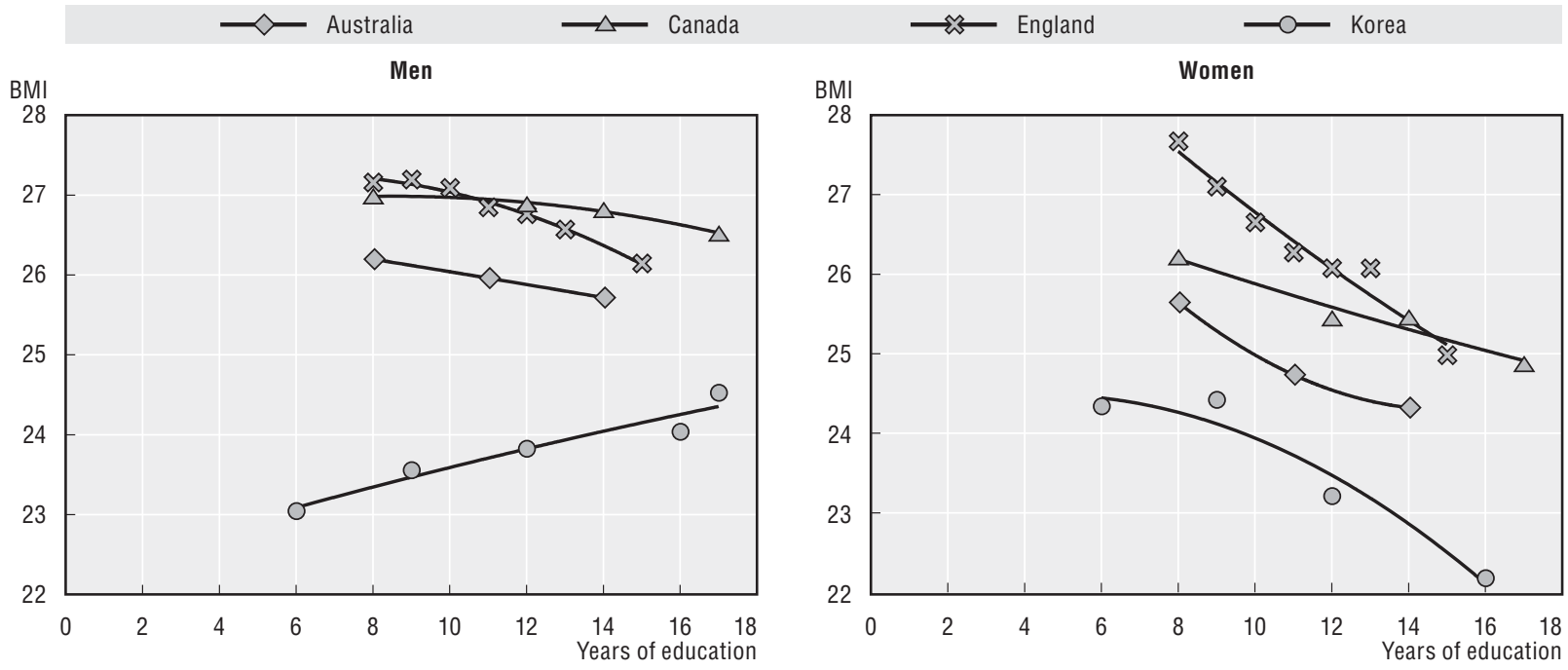

Source: Authors' estimates from linear regression, see Annex A2.

The relationship between obesity and education was observed in different sub-groups along dimensions reflecting ethnicity or minority status (Figures 4 to 6). Obesity rates presented in Figures 4 to 6 are estimates adjusted for age, gender, and socio-economic status. Full results are presented in Annex A3. Three ethnic groups were identified in England (White, Black, Asian), while binary variables were used in Canada and Australia to denote, respectively, ethnic minority status and migrant status. The slope of the correlation between education and obesity is broadly similar in women, across all ethnic groups, although Black women display significantly higher obesity rates than others. It is difficult to assess whether the different patterns observed in Black and Asian women, suggesting a concave relationship between education and obesity in the former and a 
Figure 4. Relationship between obesity and years of education by ethnicity groups in England
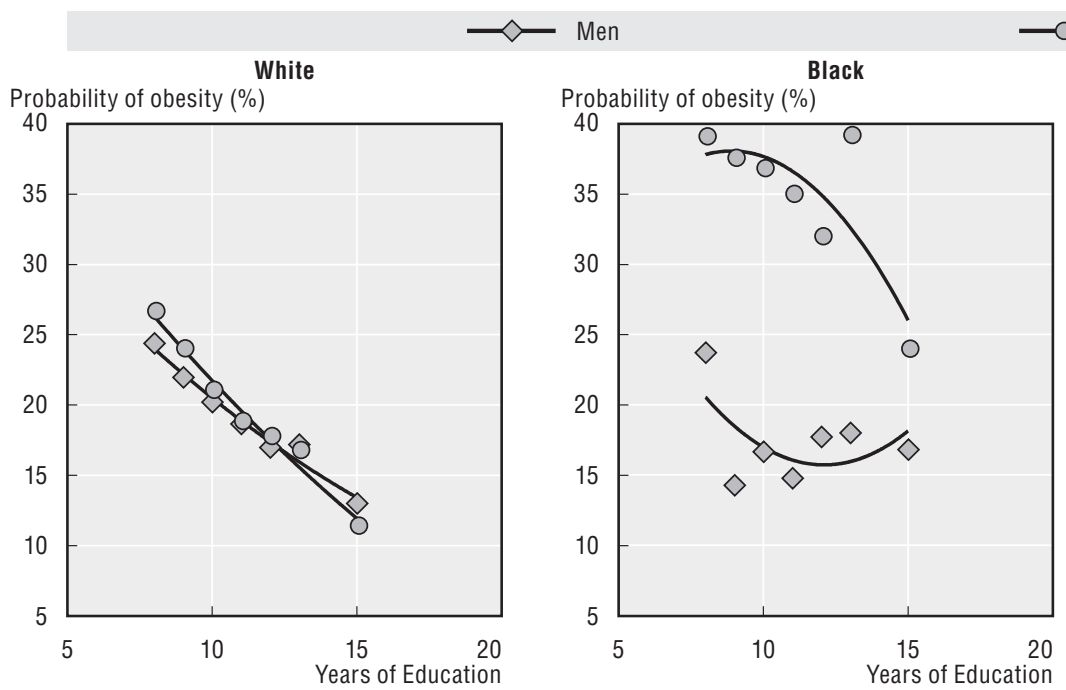
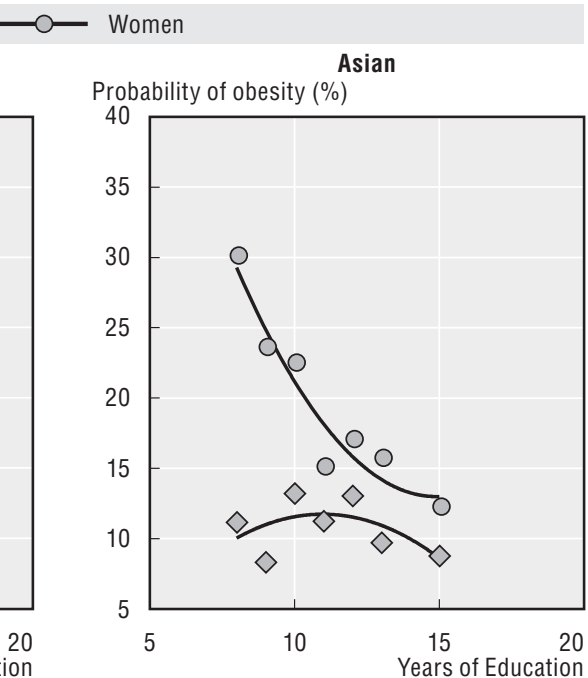

Source: Authors' estimates from logistic regression, see Annex A3.

convex relationship in the latter, reflects a true difference in the impact of education in the two groups. However, this interpretation of concavity and convexity on few data points should be taken with caution, as it is sensitive to outliers. This finding demands a larger and more detailed investigation. Education appears to be much more weakly correlated with obesity in Black and Asian men, although the least educated among Black men are substantially more likely to be obese than their more educated counterparts.

In Canada, individuals who belong to ethnic minority groups are less likely to be obese than White majority individuals. The relationship between obesity and education level is negatively sloped in both men and women, regardless of minority status, as illustrated in Figure 5.

Figure 5. Relationship between obesity and years of education by minority status in Canada
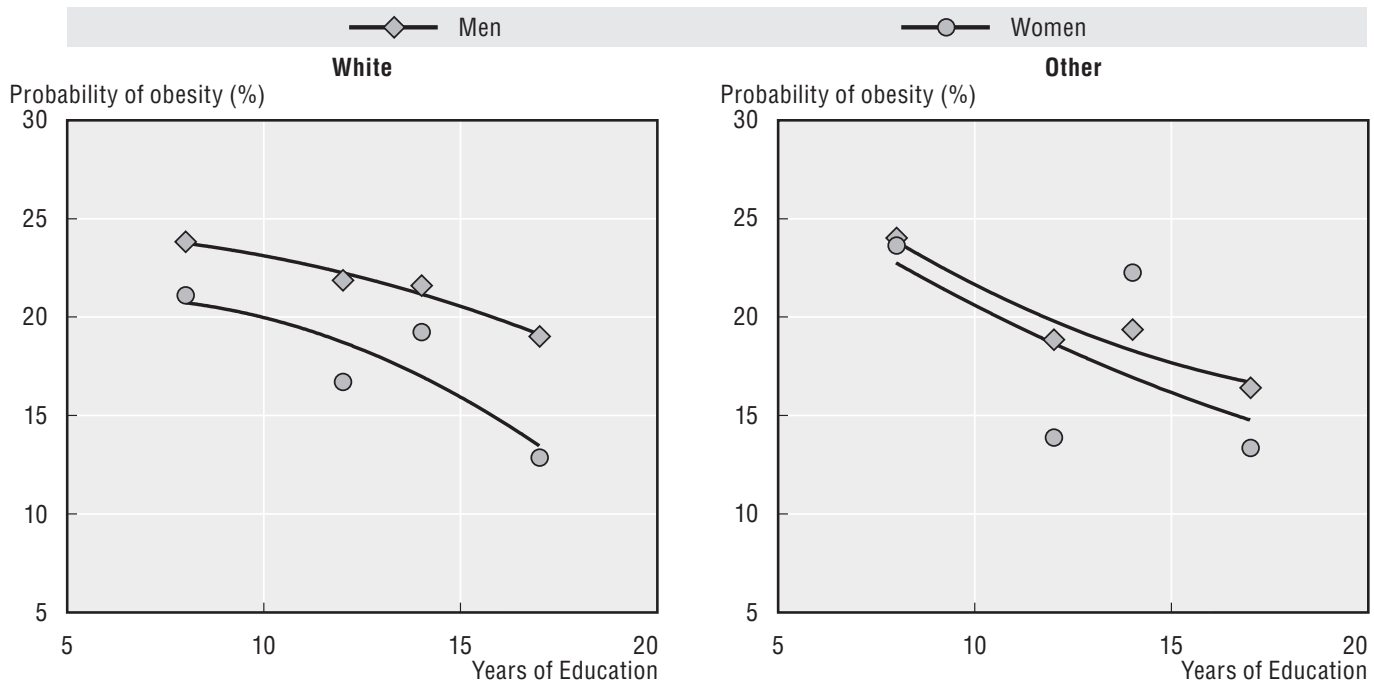

Source: Authors' estimates from logistic regression, see Annex A3. 
The analysis of the correlation between obesity and education in Australia does not show significant differences by migrant status, as illustrated in Figure 6.

Figure 6. Relationship between obesity and years of education by migrant groups in Australia
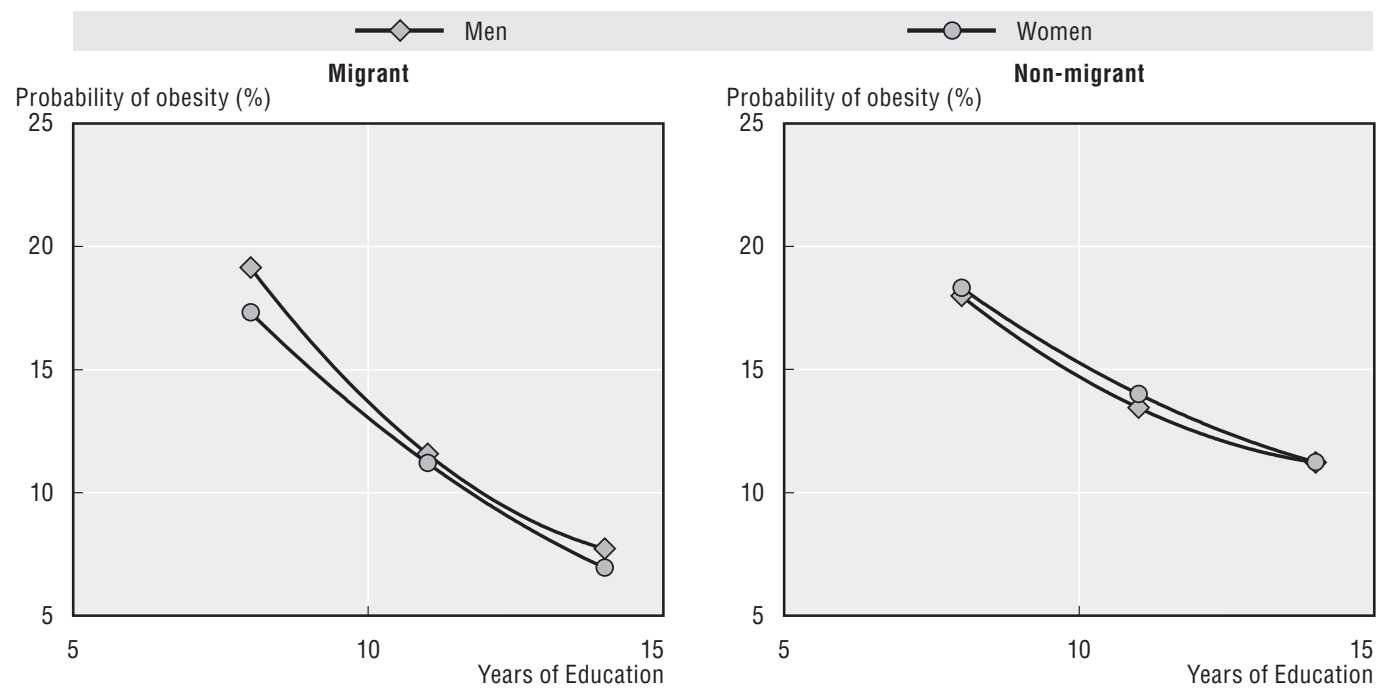

Source: Authors' estimates from logistic regression, see Annex A3.

In addition, regression analyses presented in Annexes A2 and A3 were adjusted for socio-economic status. Obesity tends to be more prevalent in disadvantaged socio-economic groups, and inequalities are consistently larger in women than in men. A more detailed analysis of social inequalities in obesity is presented in a separate study (Devaux and Sassi, 2011).

\section{Does the relationship between education and obesity reflect the role of other factors associated with individual education?}

Several factors associated with individual education may potentially have an influence on the correlation observed between education and BMI/obesity. In particular, we studied the influence of individual socio-economic status and of the education level of household members.

In addition to its direct effect on the likelihood of obesity, individual education may also have an indirect effect, mediated by individual socio-economic status. Figure 7 describes the hypothesised mediation effect. Individual education contributes to determining individual socio-economic status (a), which in turn has an influence on the likelihood of obesity (b). Such mediated effect adds to the direct effect of education on obesity $^{1}$ (c). In order to test for the existence of the hypothesised mediation effect, a series of logistic regression models were developed with and without controlling for the socioeconomic status covariate, to assess possible variations in the coefficients of the individual education variable. Results are consistent with a slight mediation role played by socioeconomic status in the relationship between education and obesity since odds ratios of obesity according to education level change slightly towards a unitary value, when the role of socio-economic status is accounted for (Sassi et al., 2009). However, it should be noted that this empirical strategy does not account for a potential reverse causality in the relationships outlined in Figure 7 ( $a, b$ and $c)$. 
Figure 7. Indirect effect of individual education through individual socio-economic status

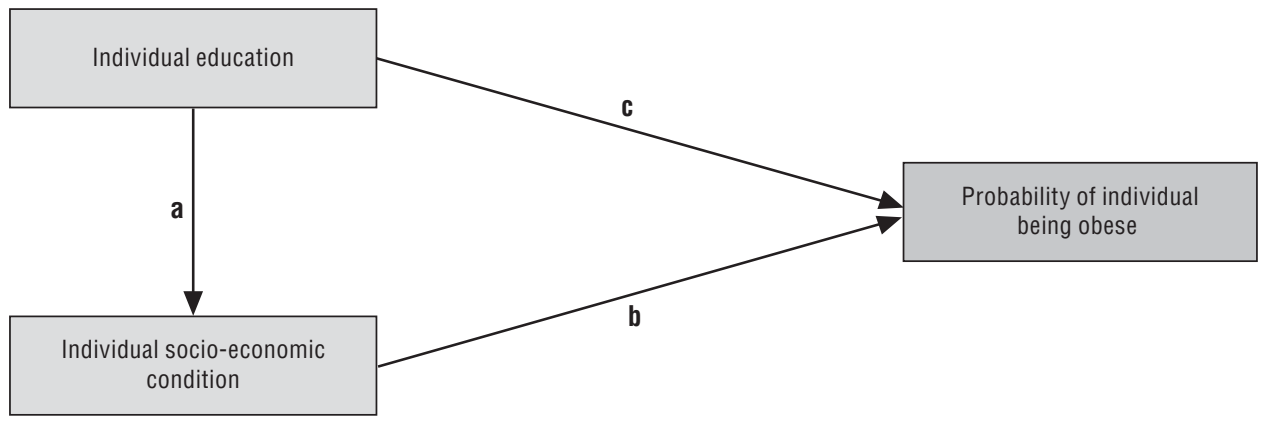

A further analysis focused on the education of household members, which might have a direct influence on the likelihood of an individual being obese, i.e. it may have a concurrent effect to that of individual education (relationships $e$ and $f$ in Figure 8). In principle, individual education may also act as a mediator of the household education effect on obesity ( $d$ and $e$ in Figure 8). However, the analysis focused on the former (concurrent) effect of the education of household members.

Figure 8. Indirect effect of education of household members

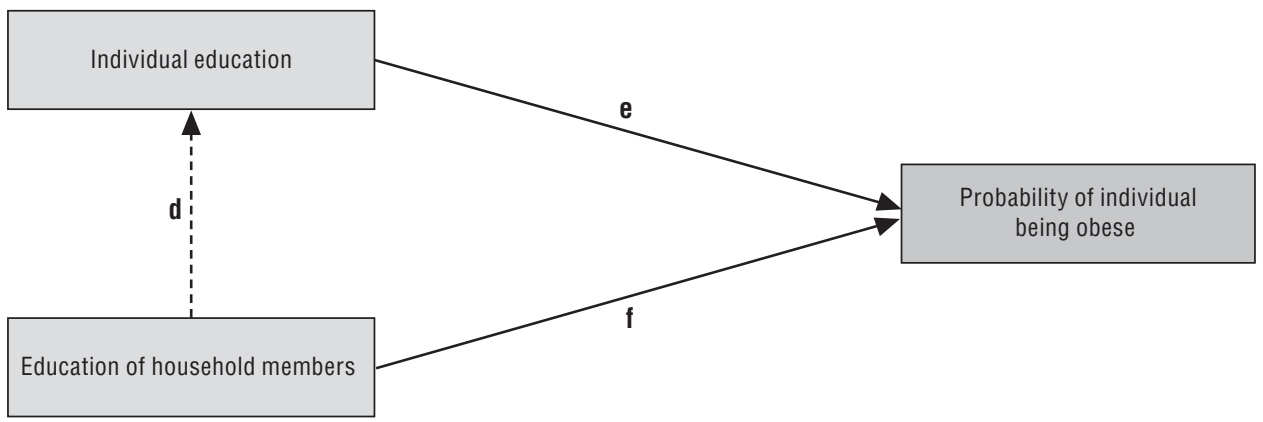

The concurrent effect of household education could bias estimates of the effect of individual education on obesity. The education of household members could be, indeed, viewed as an omitted variable that would bias the model's coefficients. So, to test for this concurrent effect, regression models with and without this covariable were computed. This analysis is limited to England and Korea, the two countries for which household-based surveys are available. Multilevel logistic models were used to account for household structure (see Annex A4 for details of methods used). The education of household members is defined as the years of education of the spouse of the head of household and, when the latter was not available, as the years of education of the head of household. ${ }^{2}$

Odds ratios for the probability of being obese in England are displayed in Table 1. Model 1 is a multilevel logistic model without controls for the level of education of household member, whereas model 2 accounts for the education of household members. Differences among households explain about one fifth of the total variance in the likelihood of obesity (see the intra-class correlation coefficient Rho, in Table 1). It is worth noting that household education is negatively correlated to obesity status (odds ratio $<1$ ) with significant values when years of education are above 11. Comparison of model 2 with model 1 shows that there seems to be a small concurrent effect of household education on 
obesity, which adds to the effect of individual education, since odds ratios of obesity according to individual education become smaller and closer to 1 .

Table 1. Odds ratios and significance for the probability of obesity in England

\begin{tabular}{|c|c|c|}
\hline \multirow{2}{*}{ England } & Model 1: without controls & Model 2: with controls for household education \\
\hline & Odds Ratios Significance & Odds Ratios Significance \\
\hline Age & $1.070^{* * *}$ & $1.073^{* * *}$ \\
\hline Age squared & $0.999^{* * *}$ & $0.999^{\star * *}$ \\
\hline Year of survey & $1.065^{* * *}$ & $1.067^{\star * *}$ \\
\hline Women & $1.441^{\star * *}$ & $1.381^{* * *}$ \\
\hline \multicolumn{3}{|c|}{ Years of education - Men } \\
\hline 8 & ref. & ref. \\
\hline 9 & 0.937 & 0.967 \\
\hline 10 & $0.860^{* *}$ & 0.916 \\
\hline 11 & $0.767^{* * *}$ & $0.859 *$ \\
\hline 12 & $0.703^{* * *}$ & $0.798^{\star \star}$ \\
\hline 13 & $0.671^{\star \star *}$ & $0.796^{\star \star \star}$ \\
\hline 15 & $0.522^{* * *}$ & $0.636^{* * *}$ \\
\hline \multicolumn{3}{|c|}{ Years of education - Women } \\
\hline 8 & ref. & ref. \\
\hline 9 & $0.746^{\star * *}$ & $0.784^{\star \star *}$ \\
\hline 10 & $0.630^{* * *}$ & $0.697^{* * *}$ \\
\hline 11 & $0.552^{* * *}$ & $0.664^{\star * *}$ \\
\hline 12 & $0.514^{* * *}$ & $0.615^{* * *}$ \\
\hline 13 & $0.505^{\star * \star}$ & $0.648^{\star * *}$ \\
\hline 15 & $0.304^{* * *}$ & $0.390^{* * *}$ \\
\hline \multicolumn{3}{|l|}{ Ethnicity } \\
\hline White & ref. & ref. \\
\hline Black & $1.714^{\star \star *}$ & $1.729 * * *$ \\
\hline Asian & $0.738^{\star * *}$ & $0.734^{* * *}$ \\
\hline \multicolumn{3}{|c|}{ Socio-economic status } \\
\hline highest & ref. & ref. \\
\hline middle-high & $1.252^{* \star *}$ & $1.253^{\star * *}$ \\
\hline middle & $1.199^{* * *}$ & $1.192^{* * *}$ \\
\hline middle-low & $1.347^{\star \star \star}$ & $1.337^{\star \star \star}$ \\
\hline lowest & $1.481^{\star * *}$ & $1.466^{\star * *}$ \\
\hline \multicolumn{3}{|c|}{ Years of education of household } \\
\hline 8 & & ref. \\
\hline 9 & & 0.951 \\
\hline 10 & & 0.893 \\
\hline 11 & & $0.812^{* *}$ \\
\hline 12 & & $0.819^{\star *}$ \\
\hline 13 & & $0.752^{\star \star *}$ \\
\hline 15 & & $0.749 * * *$ \\
\hline Observations & 102051 & 100202 \\
\hline Log-likelihood & -49860.1 & -48867.7 \\
\hline Rho & $0.195^{\star \star \star}$ & $0.196^{\star \star \star}$ \\
\hline
\end{tabular}

Note: ${ }^{* * *}$ means significant at $1 \%,{ }^{* *}$ at $5 \%,{ }^{*}$ at $10 \%$.

Source: Cross-sectional survey data from Health Survey for England 1991-2005. Authors' calculations.

Table 2 shows the results of the corresponding analysis for Korea. In this case, differences among households explain about $7 \%$ of the total variance in the likelihood of obesity (see intra-class correlation in Table 2). In both models, odds ratios for men are not significantly different from 1 , although the strength of the correlation between obesity and 
individual education is somewhat diminished in model 2, similarly to what was observed in England. On the other hand, the correlation between individual education and obesity appears marginally strengthened when accounting for household education in women, contrary to expectations. However, the absence of a statistically significant correlation between household education and obesity prevents from drawing any conclusions on the role of the latter in Korea.

\section{Table 2. Odds ratios and significance for the probability of obesity in Korea}

\begin{tabular}{|c|c|c|c|}
\hline \multirow{2}{*}{ Korea } & Model 1: without controls & \multicolumn{2}{|c|}{ Model 2: with controls for household education } \\
\hline & Odds Ratios Significance & Odds Ratios & Significance \\
\hline Age & 0.961 & \multicolumn{2}{|c|}{0.965} \\
\hline Age squared & 1.000 & \multicolumn{2}{|c|}{1.000} \\
\hline Year of survey & $1.070^{\star * *}$ & \multicolumn{2}{|c|}{$1.071^{* * *}$} \\
\hline Women & $3.871^{\star * *}$ & \multicolumn{2}{|c|}{$3.759 * \star \star$} \\
\hline \multicolumn{4}{|c|}{ Years of education - Men } \\
\hline 6 & ref. & \multicolumn{2}{|c|}{ ref. } \\
\hline 9 & 1.551 & \multicolumn{2}{|c|}{1.385} \\
\hline 12 & 1.582 & \multicolumn{2}{|c|}{1.439} \\
\hline 16 & 1.438 & \multicolumn{2}{|c|}{1.123} \\
\hline 17 & 1.810 & \multicolumn{2}{|c|}{1.209} \\
\hline \multicolumn{4}{|c|}{ Years of education - Women } \\
\hline 6 & ref. & \multicolumn{2}{|c|}{ ref. } \\
\hline 9 & 0.959 & \multicolumn{2}{|c|}{0.795} \\
\hline 12 & $0.408 * * *$ & \multicolumn{2}{|c|}{$0.394^{\star \star *}$} \\
\hline 16 & $0.189 * * *$ & \multicolumn{2}{|c|}{$0.152^{* * *}$} \\
\hline Socio-economi & & & \\
\hline highest & ref. & re & \\
\hline middle-high & 0.971 & 0.94 & \\
\hline middle & 1.006 & 0.99 & \\
\hline middle-low & 1.040 & 1.05 & \\
\hline lowest & 1.203 & 1.21 & \\
\hline Years of educa & & & \\
\hline 6 & & re & \\
\hline 9 & & 1.18 & \\
\hline 12 & & 1.05 & \\
\hline 16 & & 1.32 & \\
\hline 17 & & 2.28 & \\
\hline Observations & 15441 & 1519 & \\
\hline Log-likelihood & -2039.7 & -1998. & \\
\hline Rho & 0.077 & 0.07 & \\
\hline
\end{tabular}

Note: ${ }^{* * *}$ means significant at $1 \%,{ }^{* *}$ at $5 \%,{ }^{*}$ at $10 \%$.

Source: Cross-sectional survey data from KNHANES 1998-2005. Authors' calculations.

\section{Do the data provide evidence of the causal nature of the link between education and obesity?}

When exploring the cross-sectional relationship between obesity and education, it is difficult to interpret the direction of the causal link between the two variables. In addition, the correlations identified might be affected by the omission of relevant variables in the analysis.

The existence of a reverse causal effect (obesity in young age determines the level of educational achievement of an individual) is supported by the findings of several studies. 
Sargent and Blanchflower (1994), using panel data, showed an inverse relationship between obesity at age 16 and earnings at 23 in young women. Gortmaker et al. (1993) found that women who were overweight in childhood completed fewer years of school. Crosnoe and Muller (2004) found that students at risk of obesity achieved worse outcomes in schools characterised by higher romantic activity, lower mean BMI or lower rate of athletic participation, than they did in schools lower in romantic activity, higher in mean BMI or higher in athletic participation.

Since no suitable instrument for education was identified in the available survey data, nor could be linked from external sources, it was not possible to address endogeneity issues satisfactorily in the analysis. However, an attempt to explore the direction of the causal link between education and obesity was made possible by data from an additional country, France. ${ }^{3}$ The data from Enquête Décennale Santé 2002-2003 provides information on body weight at age 20 , which was taken to reflect obesity status at school age. The data shows that being "obese at age 20 " is positively and significantly correlated with obesity in adulthood (correlation 0.177 ) and is negatively and significantly correlated with the number of years spent in education (correlation -0.035). Figure 9 shows that those who were obese at age 20 have significantly lower levels of educational attainment than those who were not obese, suggesting a potential for reverse causality in the relationship between education and obesity.

Figure 9. Distribution of years of education according to obesity status at age 20

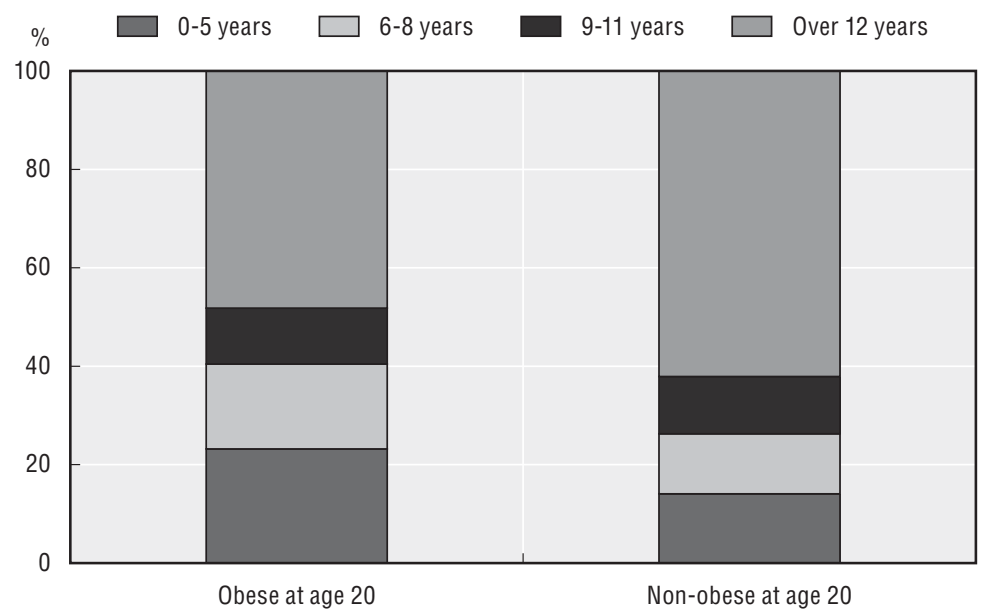

Source: French data from Enquête Décennale Santé 2002-03; Authors' calculations.

In order to assess the influence of such potential reverse causal effect on the observed correlation between education and adult obesity, the results of two regression analyses assessing factors associated with adult obesity were compared, in one the "obesity at age 20" variable was included as an additional covariate (Table 3). Comparing Model 1 (without control) and Model 2 (with control) is a way of assessing whether the strength of the association between education and obesity is affected by a potential reverse causality. Odds ratios of obesity relative to education for women are virtually identical in both models, while small changes are observed in odds ratios for men. This comparison suggests that a reverse causal effect is unlikely to have a significant influence on the strength of the correlation observed between education and adult obesity. However, there 
remains an issue of potential recall bias concerning body weight at age 20 , as suggested by the fact that individuals tended to report round numbers (e.g. 60, or $65 \mathrm{~kg}$ ).

Table 3. Odds ratios for obesity in adulthood in France (age range 25-64)

\begin{tabular}{|c|c|c|}
\hline \multirow{2}{*}{ France } & Model 1: without control for obesity at age 20 & Model 2: with control for obesity at age 20 \\
\hline & Odds Ratios Significance & Odds Ratios Significance \\
\hline Age & $1.13^{* * *}$ & $1.14^{\star \star *}$ \\
\hline Age squared & $1.00^{* * *}$ & $1.00^{* * *}$ \\
\hline Women & $1.26^{* *}$ & $1.31^{* \star}$ \\
\hline \multicolumn{3}{|l|}{ Years of education - Men } \\
\hline $0-5$ years & ref. & ref. \\
\hline $6-8$ years & 0.93 & 0.98 \\
\hline $9-11$ years & $0.75^{* *}$ & 0.79 \\
\hline over 12 years & $0.85^{\star}$ & 0.90 \\
\hline \multicolumn{3}{|c|}{ Years of education - Women } \\
\hline $0-5$ years & ref. & ref. \\
\hline $6-8$ years & $0.84^{*}$ & $0.83^{*}$ \\
\hline $9-11$ years & $0.54^{\star \star *}$ & $0.54^{\star \star *}$ \\
\hline over 12 years & $0.52^{* \star *}$ & $0.53^{* \star *}$ \\
\hline Obese at age 20 & & $15.53^{* * *}$ \\
\hline \multicolumn{3}{|l|}{ Occupation (SES) } \\
\hline Blue collar workers & ref. & ref. \\
\hline Craftsmen & $0.82^{\star \star}$ & $0.81^{* *}$ \\
\hline Farmers & 0.88 & 0.84 \\
\hline Clerks & $0.82^{\star \star *}$ & $0.82^{\star \star \star}$ \\
\hline Intermediate professions & $0.65^{\star \star \star}$ & $0.66^{* * *}$ \\
\hline Managers, Professionals & $0.42^{* * *}$ & $0.43^{\star \star *}$ \\
\hline \multicolumn{3}{|l|}{ Working status } \\
\hline Working & ref. & ref. \\
\hline Not working & $1.29^{\star \star \star}$ & $1.29^{\star \star \star}$ \\
\hline
\end{tabular}

Note: ${ }^{* * *}$ means significant at $1 \%,{ }^{* *}$ at $5 \%,{ }^{*}$ at $10 \%$.

Source: French data from Enquête Décennale Santé 2002-03. Authors' calculations.

\section{What theoretical model of the influence of education on social outcomes is supported by the data?}

As a final step in our empirical analysis, we assessed which of the absolute, relative and cumulative conceptual models of the outcomes of education proposed by Campbell (2006) is empirically supported by the data.

Table 4 indicates that better educated individuals are less likely to be obese than their less educated counterparts in all of the countries considered. This result can be viewed as evidence in support of the absolute effect of education model, mirroring evidence in the literature on the importance of individual level education for health status and health behaviours. However, after accounting for individual level education, those who are exposed to better educated environments in Australia, Canada and England are significantly more likely to be obese. This finding supports the relative model of the effects of education, which appears to play a larger role than the absolute model in explaining the distribution of obesity across social groups. The educational environment estimate is not significant in Korea which gives evidence for the absolute model.

The relative effect could operate through several pathways. One pathway that is consistent with both the absolute and the relative models is that linking social position to 


\section{Box 3. The absolute, relative and cumulative models}

The relationship between education and obesity may be interpreted according to various models/hypotheses, which involve alternative mechanisms. Three such models were conceptualised by Campbell (2006) as follows.

The absolute model implies that the probability that individuals will be obese depends on their level of education. According to this model, education may reduce the probability that an individual will be obese both by increasing the stock of information available to the individual concerning the health risks associated with unhealthy lifestyles, and by improving their ability to understand and handle such information. When the effects of education are in line with the predictions of the absolute model, policies which successfully promote education and learning and increase the average educational attainment of a population will have the effect of decreasing obesity rates. While our hypothesis is that the absolute model of education generally leads to lower rates of obesity through increased education, the absolute effect of education might also be negative. If education increases wages, and therefore increases the opportunity cost of leisure time, an educated individual's propensity to engage in leisure time physical activity or home meal preparation will likely be reduced.

The relative model implies that education serves as a marker of social status and an individuals' level of education relative to their peers, or relative to the prevailing level of education in the relevant social environment, is what affects the probability that they will be obese. This model implies that a generalised increase in the level of education of an entire community may not alter individual outcomes, unless the relative position of individuals within that community changes as a result.

The cumulative model rests on the idea that the impact of individual education on obesity is consistent with, and additive to, the impact of the level of education of other members of the same community. Therefore, the likelihood that an individual may become obese depends both on the individual's own level of education and on the level of education of other community members.

To test the above models, logistic regression analyses of the likelihood of obesity were run on the four countries' data using a similar approach to that proposed by Campbell (2006) in his analysis of civic and social engagement as an outcome of education. Regression models included, in addition to the control variables gender and age, two measures of education: the number of years of education completed by the individual respondent (education level) and the mean level of education completed by members of the same age cohort within the same country (educational environment). In order to calculate the educational environment variable, four 10-year birth cohort groups were devised: 1941-50, 1951-60, 1961-70, 1971-80. Mean education levels within each cohort were standardised using the 2005 national distributions of levels of education (lower secondary; upper secondary; tertiary education) by age group, available in Education at a Glance 2007 (OECD, 2007). Findings of a statistically-significant and strong negative effect of individual level education on obesity would provide support for the absolute model. A correlation between educational environment and obesity could be interpreted as evidence of a relative effect of education, especially if the correlation is stronger than that between individual education and obesity. Findings indicating that individual education is correlated with obesity and the educational environment variable is inversely correlated with obesity would lend support to the cumulative model, especially if the latter correlation were stronger than the former (Campbell, 2006). 
Table 4. Odds ratios and significance for likelihood of obesity when controlling for cohort education level

\begin{tabular}{|c|c|c|c|c|}
\hline & Australia & Canada & England & Korea \\
\hline Age & $1.060^{\star \star \star}$ & $1.026^{\star \star *}$ & $1.157^{\star \star \star}$ & 0.992 \\
\hline Age squared & & & $0.999^{* * *}$ & 1.000 \\
\hline Women & $0.859^{\star * *}$ & $0.808^{* * *}$ & $1.138^{* * *}$ & 1.179 \\
\hline Individual education & $0.912^{\star \star \star}$ & $0.959^{* * *}$ & $0.913^{\star * *}$ & $0.921^{\star * *}$ \\
\hline Educational environment & $3.347^{\star * *}$ & $1.184^{\star * *}$ & $2.015^{\star * *}$ & 0.989 \\
\hline \multicolumn{5}{|l|}{ Socio-economic status } \\
\hline highest & ref. & ref. & ref. & ref. \\
\hline middle-high & $1.179^{\star \star \star}$ & $1.099 * * *$ & $1.232^{\star \star \star}$ & 0.946 \\
\hline middle & $1.158^{\star * *}$ & $1.104^{* * *}$ & $1.221^{* * *}$ & 0.912 \\
\hline middle-low & $1.531^{\star \star \star}$ & $1.106^{\star \star}$ & $1.397^{\star \star *}$ & 1.057 \\
\hline lowest & $1.365^{\star \star \star}$ & $1.189^{\star * *}$ & $1.488^{\star \star *}$ & 1.200 \\
\hline \multicolumn{5}{|l|}{ Ethnicity } \\
\hline White & & & ref. & \\
\hline Black & & & $1.675^{\star \star \star}$ & \\
\hline Asian & & & $0.780^{\star * \star}$ & \\
\hline
\end{tabular}

In Australia and Canada age squared is not available as the age variable is categorical; we use mid-age of each category. $^{* * *}$ means significant at $1 \%,{ }^{* *}$ at $5 \%,{ }^{*}$ at $10 \%$.

Source: Authors' calculations based on national survey data.

stress levels and eventually to health outcomes. Evidence has been gathered that individuals who have a lower social position are exposed to higher levels of perceived stress, because of a lower degree of control over their jobs and their life circumstances and because of a less satisfactory balance between efforts and rewards (Siegrist and Marmot, 2004). This is associated with a reduced ability to handle environmental pressures and often translates into less healthy lifestyles, obesity, chronic diseases and premature mortality (Brunner et al, 2007; Chandola et al., 2008). A second pathway which typically reflects features of the relative model of the effects of education is linked to a higher demand for health inputs that are associated with a healthy weight, e.g. gym and health club memberships, by those who have higher levels of education and occupy higher social positions. In communities where the average level of education is higher, demand for such inputs, and consequently the price of those inputs, are also likely to be higher, hindering access to the same resources for the less educated and less well-off.

A further analysis was carried out to test for a possible effect of individual education on obesity, consistent with the absolute model discussed above. The analysis exploited ageperiod-cohort models of obesity developed by Sassi et al (2009) with the aim of disentangling the effects of the three time-related factors (individual age, period of observation and birth cohort) on the likelihood of obesity. The findings of the main analysis showed negatively sloped cohort effects, suggesting that individuals born in more recent cohorts, other things being equal (including age), have a lower probability of being obese than individuals born in earlier cohorts, with a possible flattening of the cohort effect curve for the most recent cohorts. Here, these models were completed by adding a control for individual education, for the purpose of testing whether improvements in education over time may account for at least part of the negatively sloped cohort effects observed in the main analysis, i.e. whether a higher level of education may partly explain why individuals born in more recent cohorts have a lower probability of being obese. The age-period-cohort model used in the analyses is the one proposed by Yang, Fu and Land (2004), based on a robust estimator (intrinsic estimator) which does not require the identification of 
constraints on the parameter vector by using prior information. The intrinsic estimator method (Fu, 2000; Knight and Fu, 2000; Fu and Hall, 2004; Fu and Rohan, 2004) considers an orthogonal decomposition of the parameter space into a null space for the singular design matrix and a non-null space, where the intrinsic estimator is obtained by the MoorePenrose generalised inverse. Analyses were carried out on data from Canada and England. Obesity rates in Korea are too low for this analysis to produce meaningful results, and Australian data were not directly accessible at the individual level.

Figure 10. Negative cohort effect with/without controls for education level in England

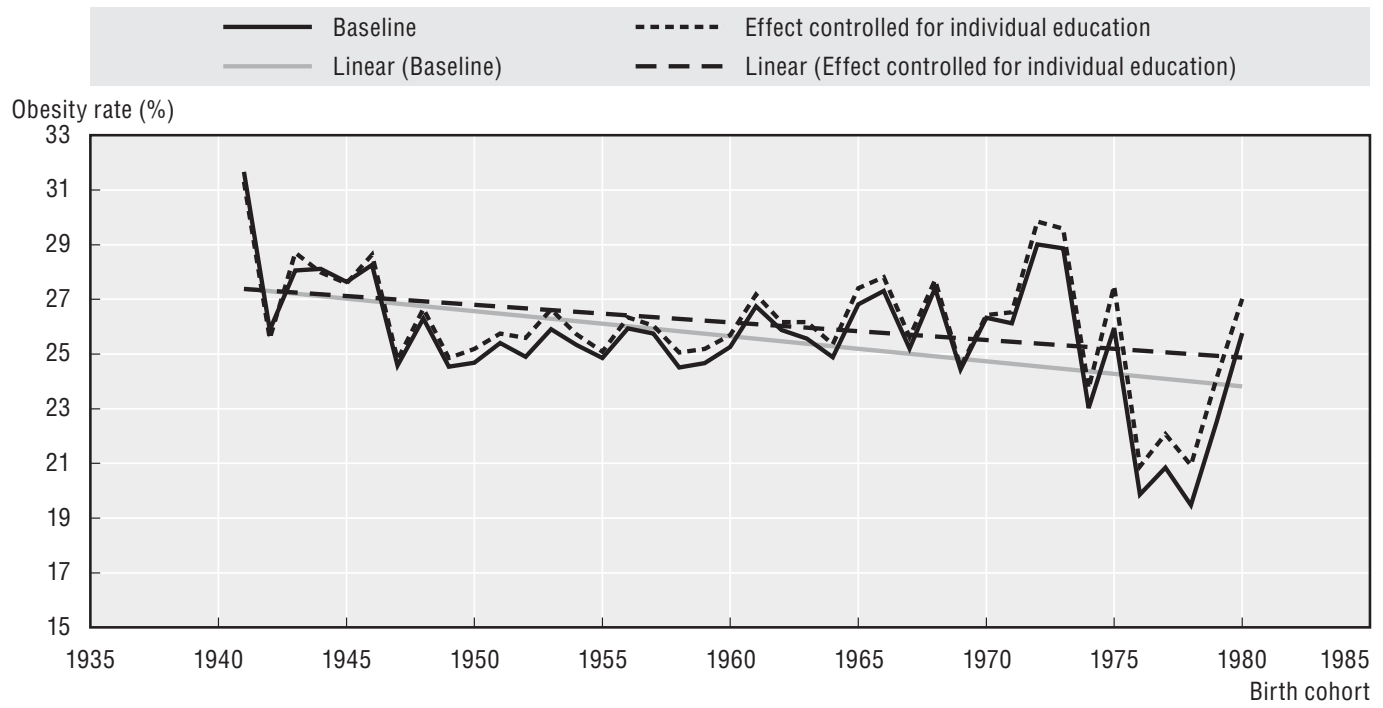

Source: Authors' calculation based on national survey data.

Figure 11. Negative cohort effect with/without controls for education level in Canada

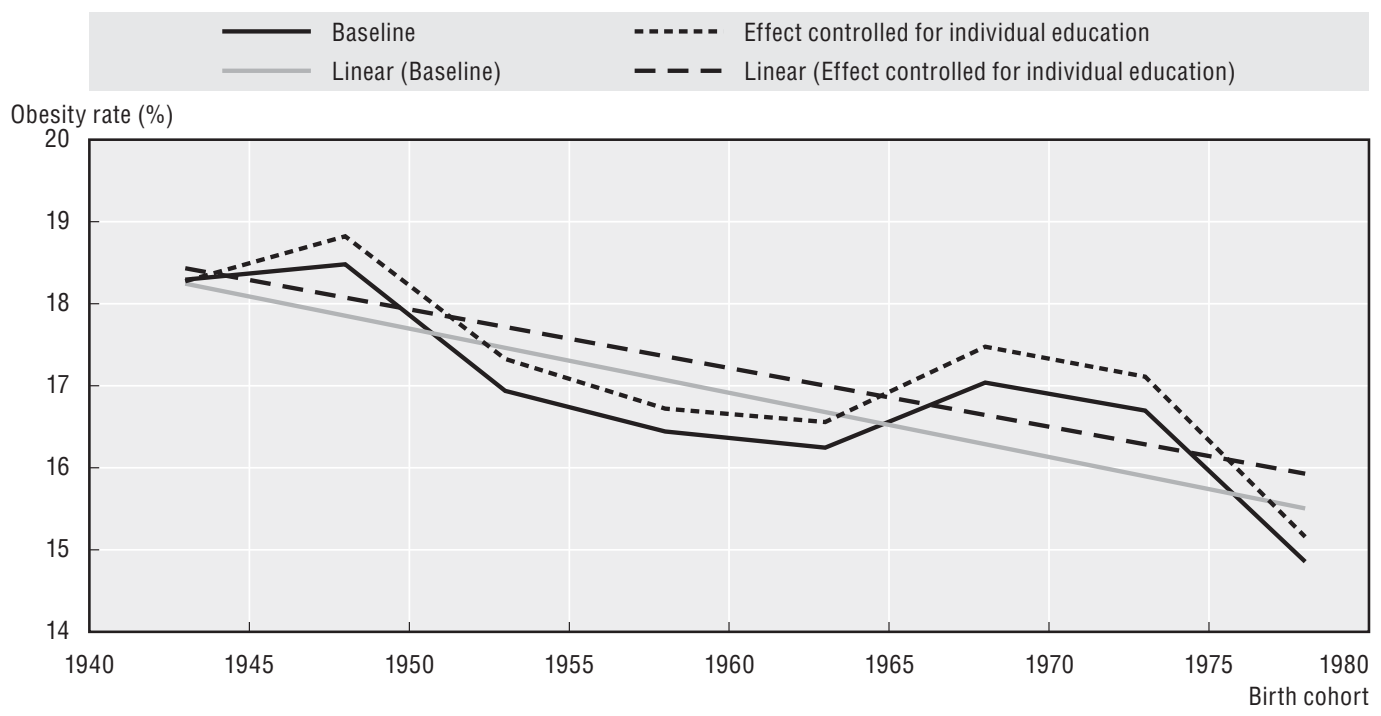

Source: Authors' calculation based on national survey data.

An age-period-cohort analysis allowed to disentangle the impact of the three timerelated effects on obesity. The findings of such analysis (reported in Sassi et al., 2009) show 
declining cohort effects in Canada, England and, to a lesser degree, in Korea (no APC analysis could be undertaken on Australian data). After inclusion of individual education as a covariate in the regression models for the two countries with more pronounced cohort effects, trends in cohort effects become more flat (Figures 10 and 11). This means that part of the reduction in the likelihood of obesity in younger birth cohorts is explained by their higher degrees of educational attainment achieved by individuals in the same cohorts, which is consistent with the absolute model of the effects of education on obesity.

\section{Conclusions}

A range of analyses of health survey data from Australia, Canada, England and Korea were undertaken with the aim of exploring the relationship between education and obesity. The findings of these analyses show a broadly linear relationship between the number of years spent in full-time education and the probability of obesity, with most educated individuals displaying lower rates of the condition (the only exception being men in Korea). This suggests that the strength of the correlation between education and obesity is approximately constant throughout the education spectrum. Increasing education at any point along that spectrum would be expected to reduce obesity to a similar degree, if the causal nature of the link between education and obesity had been established.

The education gradient in obesity is stronger in women than in men. Differences between genders are minor in Australia and Canada, more pronounced in England and major in Korea. The gradient has not meaningfully changed over the time periods covered by the health survey data available for our study. However, there is at least some evidence that over longer periods of time more educated individuals have been less likely to be become obese than their less educated counterparts, suggesting that education produces its influence on obesity only in the long term.

The causal nature of the link between education and obesity has not yet been proven with certainty. Our own attempt to use a natural experiment, involving a school reform which increased the minimum compulsory schooling age in England by one year in 1973, failed to establish a causal link. However, using data from France we were able to ascertain that the direction of causality appears to run mostly from education to obesity, as the strength of the association is only minimally affected when accounting for reduced educational opportunities for those who are obese in young age. Most of the effect of education on obesity is direct. Small components of the overall effect of education on obesity are mediated by an improved socio-economic status linked to higher levels of education, and by a higher level of education of other family members, associated with an individual's own level of education.

The positive effect of education on obesity is likely to be determined by at least three factors: a) greater access to health-related information and improved ability to handle such information; b) clearer perception of the risks associated with lifestyle choices; and, c) improved self-control and consistency of preferences over time. However, it is not just the absolute level of education achieved by an individual that matters, but also how such a level of education compares with that of the individual's peers. The higher the individual's education relative to his or her peers, the lower is the probability of the individual being obese. The latter effect may be due to different levels of perceived stress experienced by individuals in different social positions, and by different coping mechanisms. Access to 
resources required to maintain a healthy weight may also be driven by an individual's position in the social hierarchy.

The findings reported in this paper concerning the relationship between education and obesity are consistent with those reported in a number of other studies, notably Spasojevic (2003), Arendt (2005), Kenkel et al. (2006), Cutler and Lleras-Muney (2006), Sánchez-Vaznaugh et al. (2009). Several of the above studies showed a strong education gradient in BMI or obesity, with the better educated, especially if women, less likely to be overweight or obese. We found similar evidence in all of the four countries examined, with the largest differences between genders in Korea, the only country in which an inverse gradient (more education associated with higher obesity rates) was observed in men. This used to be a common pattern in many countries early in the $20^{\text {th }}$ century, and it is possible that some countries which still display relatively low obesity rates, like Korea, still retain that feature as a sign of the slower transition they have been experiencing in the weight distribution across population groups. Cutler and Lleras-Muney (2006) also found that the gradient in obesity was steeper in whites than in ethnic minorities. In our study, a detailed analysis by ethnic group could be undertaken using data from England, which showed substantially milder education gradients in obesity for minority men, relative to white men, but similar gradients in women of different ethnic backgrounds.

It should be noted that BMI was measured in England and Korea, but self-reported in Canada and Australia. The use of self-reported data may potentially cause bias in the results, as a number of people tend to report incorrectly their height and weight. However, there is no clear evidence that self-report bias may vary among individuals with different levels of education. Therefore, the correlations reported in this paper may not be affected in a major way by this potential limitation. Also, BMI is not an accurate measure of body fat, or body composition. For instance, those with a substantial muscular mass because of intense physical activity may have a high BMI but a low risk for chronic diseases. However, BMI is a widely reported measure which has proven to be particularly useful in populationlevel analyses. There is evidence that the link between BMI and the associated health risks is different in Asian populations, suggesting that lower BMI thresholds should be used in the latter to identify individuals who are overweight or obese. In the present study we applied the same thresholds in all countries.

The analyses presented in this paper were based on cross-sectional health survey data, which provide a very detailed source of information on the health and health-related behaviour of the respective populations, but at the same time present a number of limitations, especially in the assessment of the causal nature of the link between education and obesity. Individual education was defined as the number of years spent in full-time education, although this was available in a discrete form and interpolations were required. No information was available on the quality and contents of the education received, which are also likely to influence health and health-related behaviour in adult life.

\section{Policy Implications}

Establishing the causal nature of links between obesity and policy levers that could potentially be used to curb the current epidemic is essential for effective policies to be designed and implemented. If changes in education could be expected to influence healthrelated behaviours and obesity rates in a population, this might strengthen the case for 
educational policies aimed, for instance, at increasing compulsory schooling age or increasing enrolment in higher education. Our analysis in Table 4 provides an estimate of the size of such effect. Increasing education by one year in the whole population would decrease the overall obesity rate by $4 \%$ in Canada, and up to $9 \%$ in England. Cutler and Lleras-Muney (2006), with reference to the broader health effects of education, argued that if a causal link were proven, education subsidies might be desirable. These would promote higher levels of education for a larger share of the population and correspondingly improve population health. Grossman and Kaestner (1997) argued that education policies directed at disadvantaged groups might reduce some of the existing health disparities. Although the evidence currently available, including some of the findings of our study, provides strong suggestions that at least part of the correlation between education and obesity is of a causal nature, conclusive proof of this does not yet exist.

Health education programmes aimed at promoting healthy lifestyles might in principle generate similar effects to those associated with school education by providing relevant information. However, Speakman et al. (2005) argue that these campaigns are likely to be ineffective "if people in lower social strata already know what foods have high energy contents, but fail to act on this information", suggesting that health promotion would mostly help those who have a higher level of education. However, very limited empirical evidence exists concerning the effects of health education programmes, and virtually none is available on differences in effectiveness between socio-economic groups. Haas (2008) suggested that more funding should not be spent on public health education campaigns while clear evidence of the effectiveness of such programmes does not exist.

Whether through formal schooling or health promotion campaigns, education may play a role in tackling overweight and obesity. Policy makers need to consider what levels of evidence should be deemed sufficient to prompt action, and how efficiency and equity objectives should be balanced in tackling obesity. Education policies aimed at increasing formal schooling include a flexible range of policies, which may be targeted at specific age and socio-economic groups. We showed that the strength of the link between education and obesity is approximately constant throughout the education spectrum, which means that similar gains could be achieved in terms of reduction of obesity rates by increasing educational attainment for early school leavers as well as for those who spend the longest in full time education. However, policies targeting early school leavers would likely improve equity by focusing on individuals who are more likely to belong to disadvantaged socio-economic groups. Similar results could be achieved by improving access to education, e.g. through financial incentives, for disadvantaged groups.

\section{Notes}

1. The assumption on the direction of the causal link from the former to the latter is further discussed later in the paper.

2. We tested whether this distinction in the construction of the variable had an effect on obesity status by introducing a control dummy variable, but it was not significant.

3. A second test for the causal nature of the link between education and obesity was carried out using data from the Health Survey for England in a sort of natural experiment, assessing the impact of the educational reform introduced in England in 1973, which increased the minimum compulsory schooling age from 15 to 16 years. Clark and Royer (2008) used this approach with reference to an earlier educational reform implemented in England in 1947, which also increased the minimum compulsory schooling age in the country, from 14 to 15 . They found that cohorts affected by the law display only slightly improved long-run health outcomes and their findings did not support a 
causal link between education and obesity. Our results consistently indicated an absence of change in the likelihood of obesity in the cohorts affected by the educational reform, relative to previous cohorts. This finding does not necessarily indicate that the link between education and obesity is not of a causal nature. Rather, it may suggest that school reforms leading to small changes in minimum compulsory schooling age do not provide sufficiently strong means for implementing an instrumental variables approach.

\section{References}

Aitkin, M., D. Anderson and J. Hinde (1981), "Statistical Modelling of Data on Teaching Styles (with Discussion)”, Journal of Royal Statistic Society, A 144, pp. 148-61.

Aitkin, M. and N.T. Longford (1986), "Statistical Modelling Issues in School Effectiveness Studies (with Discussion)", Journal of Royal Statistic Society, A 149, pp. 1-43.

Arendt, J.N. (2004), "Does Education Cause Better Health? A Panel Data Analysis Using School Reforms for Identification", Economics of Education Review, Vol. 24, No. 2, pp. 149-60.

Appiah, E. and W.W. McMahon (2002), "The Social Outcomes of Education and Feedbacks on Growth in Africa", Journal of Development Studies, 38(4), pp. 27-68.

Branca, F., H. Nikogosian and T. Lobstein (eds.) (2007), "The Challenge of Obesity in the WHO European Region and the Strategies for Response", WHO Regional Office for Europe, Copenhagen.

Brunello, G. and B. d'Hombres (2006), "Does Body Weight affect Wages? Evidence from Europe", "Marco Fanno" Working Papers 0027, Dipartimento di Scienze Economiche "Marco Fanno".

Brunello, G., D. Fabbri and M. Fort (2009), "Years of Schooling, Human Capital and the Body Mass Index of European Females". IZA Discussion Paper No. 4667. Available at http://ftp.iza.org/dp4667.pdf.

Brunner, E.J., T. Chandola and M. Marmot (2007), "Prospective Effect of Job Strain on General and Central Obesity in the Whitehall II Study", American Journal of Epidemiology, Vol. 165(7), pp. 828-37.

Campbell, D.E. (2006), “What is Education's Impact on Civic and Social Engagement?”, R. Desjardins and T. Schuller (eds.), Measuring the Effects of Education on Health and Civic/social Engagement, OECD/ CERI, Paris, pp. 25-126.

Card, D. (2001), "Estimating the Return to Schooling: Progress on some Persistent Econometric Problems", Econometrica, 69(5), pp. 1127-1160.

Cawley, J. (2004), “The Impact of Obesity on Wages”, Journal of Human Resources, Vol. 39(2), pp. 451-474.

Chandola. T., A. Britton, E. Brunner, H. Hemingway, M. Malik, M. Kumari, E. Badrick, M. Kivimaki and M. Marmot (2008), "Work Stress and Coronary Heart Disease: What are the Mechanisms?", European Heart Journal, Vol. 29(5), pp. 640-8.

Clark, D. and H. Royer (2008), “The Effect of Education on Adult Mortality and Health: Evidence from the United Kingdom", www.frbsf.org/economics/conferences/0806/royer.pdf, accessed on 8 April 2009

Crosnoe, R. and C. Muller (2004), "Body Mass Index, Academic Achievement, and School Context: Examining the Educational Experiences of Adolescents at Risk of Obesity", Journal of Health and Social Behavior, Vol. 45 (December), pp. 393-407.

Cutler, D. and A. Lleras-Muney (2006), "Education and Health: Evaluating Theories and Evidence", NBER Working Paper 12352, www.nber.org/papers/w12352.

Datar, A. and R. Sturm (2006), "Childhood Overweight and Elementary School Outcomes”, International Journal of Obesity 30, pp. 1449-60.

Devaux, M. and F. Sassi (2011), "Social Inequalities in Obesity and Overweight in 11 OECD Countries", The European Journal of Public Health, doi: http://dx.doi.org/10.1093/eurpub/ckr058.

Fu, W.J. (2000), "Ridge Estimator in Singular Design with Application to Age-Period-Cohort Analysis of Disease Rates", Communications in Statistics-Theory and Method, Vol. 29, pp. 263-278.

Fu, W.J. and P. Hall (2004), "Age-Period-Cohort Analysis: Structure of Estimators, Estimability, Sensitivity and Asymptotics", Journal of the American Statistical Association, under review.

Fu, W.J. and T.E. Rohan (2004), "Age-Period-Cohort Analysis: Consistent Estimation by the Intrinsic Estimator", Journal of the American Statistical Association, under review.

Goldstein, H. (1986), "Multilevel Mixed Linear Model Analysis Using Iterative Generalized Least Squares", Biometrika, 73, pp. 43-56. 
Gortmaker, S.L. et al. (1993), "Social and Economic Consequences of Overweight in Adolescence and Young Adulthood", The New England Journal of Medicine, Vol. 329(14), pp. 1008-12.

Grabner, M. (2009), “The Causal Effect of Education on Obesity: Evidence from Compulsory Schooling Laws". Available at SSRN: http://ssrn.com/abstract=1505075 (11 Feb. 2010).

Grossman, M. and R. Kaestner (1997), "Effects of Education on Health", J.R. Behrman and N. Stacey (eds.), The Social Benefits of Education, University of Michigan Press, Ann Arbor, MI, pp. 69-123.

Grossman, M. (2000), “The Human Capital Model”, A.J. Culyer and J.P. Newhouse (eds.), Handbook of Health Economics, Vol. 1A, Elsevier, Amsterdam, pp. 347-408.

Haas, M. (2008), “Weigh Too Fat”, UTS Speaks, Public Lecture 22 May 2008. Available on: www.chere.uts.edu.au/pdf/utspeaks_haas.pdf.

Kemna, H. (1987), "Working Conditions and the Relationship between Schooling and Health", Journal of Health Economics, Vol. 6, pp. 189-210.

Kenkel, D.S. (1991), "Health Behavior, Health Knowledge, and Schooling”, Journal of Political Economy, Vol. 99(2), pp. 287-305.

Kenkel, D.S., D.R. Lillard and A.D. Mathios (2006), "The Roles of High School Completion and GED Receipt in Smoking and Obesity", NBER Working Papers 11990, www.nber.org/papers/w11990.

Knight, K. and W.J. Fu (2000), “Asymptotics for Lasso-type Estimators”, Annals of Statistics, Vol. 28, pp. 1356-1378.

Lleras-Muney, A. (2005), “The Relationship between Education and Mortality in the US”. Review of Economic Studies, 72(1), pp. 189-221.

Lochner, L. and E. Moretti (2004), "The Effect of Education on Crime: Evidence from Prison Inmates, Arrests, and Self-reports", American Economic Review, 94(1), pp. 155-189.

Longford, N.T. (1987), "A Fast Scoring Algorithm for Maximum Likelihood Estimation in Unbalanced Mixed Models with Nested Random Effects", Biometrika, 74, pp. 817-827.

Lundborg, P. (2008), “The Health Returns to Education - What Can We Learn from Twins?", Tinbergen Institute Discussion Paper No. TI 08-027/3, Available at SSRN: http://ssrn.com/abstract=1113685.

McMahon, W.W. (2004), "The Social and External Benefits of Education”, in International Handbook on the Economics of Education, Geraint and Jill Johnes (eds), Edward Elgar, Publishers.

OECD (2007), Education at a Glance, OECD, Paris

Raudenbush, S.W. and A.S. Bryk (1986), “A Hierarchical Model for Studying School Effects”, Sociology of Education, 59, pp. 1-17.

Sánchez-Vaznaugh, E.V., I. Kawachi, S.V. Subramanian, B.N. Sánchez, D. Acevedo-Garcia (2009), "Do Socioeconomic Gradients in Body Mass Index Vary by Race/Ethnicity, Gender and Birthplace?", American Journal of Epidemiology, Vol. 169(9), pp. 1102-12.

Sargent, J.D. and D.G. Blanchflower (1994), “Obesity and Stature in Adolescence and Earnings in Young Adulthood", Archives of Pediatrics and Adolescent Medicine, Vol. 148, pp. 681-687.

Sassi, Franco et al., (2009), "The Obesity Epidemic: Analysis of Past and Projected Future Trends in Selected OECD Countries", OECD Health Working Paper No. 45, Directorate for Employment, Labour, and Social Affairs, OECD, www.oecd.org/els/health/workingpapers

Siegrist, J., M. Marmot (2004), "Health Inequalities and the Psychosocial Environment - Two Scientific Challenges", Social Science and Medicine, Vol. 58(8), pp. 1463-73.

Spasojevic, J. (2003), "Effects of Education on Adult Health in Sweden: Results from a Natural Experiment”, PhD diss., Graduate Center, City University of New York.

Speakman, J.R. et al. (2005), "Associations between BMI, Social Strata and the Estimated Energy Content of Foods", International Journal of Obesity, Vol. 29(10), pp. 1281-8.

Wardle, J., J. Waller and M.J. Jarvis (2002), "Sex Differences in the Association of Socioeconomic Status with Obesity", American Journal of Public Health, Vol. 92, pp. 1299-1304.

Webbink, D., N.G. Martin and P.M. Visscher (2008), "Does Education Reduce the Probability of Being Overweight?", CPB Discussion Papers 102, CPB Netherlands Bureau for Economic Policy Analysis.

Wolfe, B.L. and R.H. Haveman (2002), "Social and Nonmarket Benefits from Education in an Advanced Economy," Conference Series [Proceedings], Federal Reserve Bank of Boston, June, pp. 97-142. 
World Health Organisation (2003), "Diet, Nutrition and the Prevention of Excess Weight Gain and Obesity”, Report of a joint WHO/FAO expert consultation, Geneva.

Yang, Y., W. Fu and K. Land (2004), "A Methodological Comparison of Age-Period Cohort Models: the Intrinsic Estimator and Conventional Generalized Linear Models”, Sociological Methodology, Vol. 34, Issue 1, pp. 75-110.

Yoon, Y.S., S.W. Oh and H.S. Park (2006), “Socio-Economic Status in Relation to Obesity and Abdominal Obesity in Korean Adults: A Focus on Sex Differences”, Obesity (Silver Spring), Vol. 14(5), pp. 909-19. 
ANNEX A1

\section{Data Description Tables}

Table A1.1. Australia - National Health Survey

\begin{tabular}{|c|c|c|c|c|c|c|c|c|c|c|c|c|c|}
\hline \multirow{2}{*}{ Australia } & & \multicolumn{3}{|c|}{1989} & \multicolumn{3}{|c|}{1995} & \multicolumn{3}{|c|}{2001} & \multicolumn{3}{|c|}{2005} \\
\hline & & Men & Women & Total & Men & Women & Total & Men & Women & Total & Men & Women & Total \\
\hline Total frequency & & 12499 & 12490 & 24989 & 10932 & 10904 & 21836 & 4744 & 5164 & 9908 & 5348 & 5590 & 10938 \\
\hline \multirow[t]{8}{*}{ Age group } & $25-39$ & $16.5 \%$ & $16.7 \%$ & $16.6 \%$ & $15.3 \%$ & $15.6 \%$ & $15.4 \%$ & $11.4 \%$ & $12.8 \%$ & $12.1 \%$ & $12.4 \%$ & $12.9 \%$ & $12.7 \%$ \\
\hline & $30-34$ & $16.2 \%$ & $16.5 \%$ & $16.4 \%$ & $15.9 \%$ & $16.1 \%$ & $16.0 \%$ & $13.9 \%$ & $15.1 \%$ & $14.4 \%$ & $14.4 \%$ & $15.0 \%$ & $14.7 \%$ \\
\hline & $35-39$ & $15.1 \%$ & $15.4 \%$ & $15.2 \%$ & $15.2 \%$ & $15.6 \%$ & $15.4 \%$ & $14.9 \%$ & $15.4 \%$ & $15.1 \%$ & $13.9 \%$ & $14.4 \%$ & $14.1 \%$ \\
\hline & $40-44$ & $14.6 \%$ & $14.5 \%$ & $14.5 \%$ & $14.0 \%$ & $14.0 \%$ & $14.0 \%$ & $15.2 \%$ & $14.3 \%$ & $14.8 \%$ & $14.4 \%$ & $14.6 \%$ & $14.5 \%$ \\
\hline & $45-49$ & $11.7 \%$ & $11.1 \%$ & $11.4 \%$ & $12.9 \%$ & $13.1 \%$ & $13.0 \%$ & $13.3 \%$ & $13.2 \%$ & $13.2 \%$ & $13.2 \%$ & $13.2 \%$ & $13.2 \%$ \\
\hline & $50-54$ & $9.4 \%$ & $9.2 \%$ & $9.3 \%$ & $10.7 \%$ & $10.1 \%$ & $10.4 \%$ & $13.1 \%$ & $12.1 \%$ & $12.6 \%$ & $11.6 \%$ & $11.3 \%$ & $11.5 \%$ \\
\hline & $55-59$ & $8.3 \%$ & $8.2 \%$ & $8.2 \%$ & $8.7 \%$ & $8.0 \%$ & $8.4 \%$ & $10.1 \%$ & $9.3 \%$ & $9.7 \%$ & $11.3 \%$ & $10.3 \%$ & $10.8 \%$ \\
\hline & $60-64$ & $8.2 \%$ & $8.5 \%$ & $8.3 \%$ & $7.4 \%$ & $7.4 \%$ & $7.4 \%$ & $8.2 \%$ & $7.8 \%$ & $8.0 \%$ & $8.8 \%$ & $8.2 \%$ & $8.5 \%$ \\
\hline \multirow[t]{5}{*}{ Equivalized income } & upper & $31.6 \%$ & $26.9 \%$ & $29.3 \%$ & $30.0 \%$ & $26.0 \%$ & $28.0 \%$ & $31.3 \%$ & $25.7 \%$ & $28.6 \%$ & $30.4 \%$ & $24.4 \%$ & $27.5 \%$ \\
\hline & upper middle & $25.6 \%$ & $23.6 \%$ & $24.6 \%$ & $23.6 \%$ & $22.3 \%$ & $23.0 \%$ & $22.5 \%$ & $21.9 \%$ & $22.2 \%$ & $24.4 \%$ & $21.0 \%$ & $22.8 \%$ \\
\hline & middle & $20.0 \%$ & $19.5 \%$ & $19.8 \%$ & $18.8 \%$ & $18.5 \%$ & $18.7 \%$ & $19.4 \%$ & $19.2 \%$ & $19.3 \%$ & $19.8 \%$ & $21.1 \%$ & $20.4 \%$ \\
\hline & lower middle & $13.9 \%$ & $17.4 \%$ & $15.6 \%$ & $12.7 \%$ & $16.5 \%$ & $14.6 \%$ & $12.9 \%$ & $16.0 \%$ & $14.4 \%$ & $14.5 \%$ & $17.1 \%$ & $15.8 \%$ \\
\hline & lower & $8.9 \%$ & $12.6 \%$ & $10.7 \%$ & $15.0 \%$ & $16.6 \%$ & $15.8 \%$ & $13.9 \%$ & $17.1 \%$ & $15.5 \%$ & $10.9 \%$ & $16.4 \%$ & $13.6 \%$ \\
\hline \multirow[t]{2}{*}{ Migrant } & yes & $31.2 \%$ & $29.2 \%$ & $30.2 \%$ & $29.8 \%$ & $29.2 \%$ & $29.5 \%$ & $29.2 \%$ & $28.9 \%$ & $29.1 \%$ & $28.4 \%$ & $28.9 \%$ & $28.7 \%$ \\
\hline & no & $68.8 \%$ & $70.8 \%$ & $69.8 \%$ & $70.2 \%$ & $70.8 \%$ & $70.5 \%$ & $70.8 \%$ & $71.1 \%$ & $70.9 \%$ & $71.6 \%$ & $71.1 \%$ & $71.3 \%$ \\
\hline \multirow[t]{2}{*}{ Obese } & no & $90.8 \%$ & $89.6 \%$ & $90.2 \%$ & $86.4 \%$ & $86.5 \%$ & $86.4 \%$ & $82.8 \%$ & $81.8 \%$ & $82.3 \%$ & $78.1 \%$ & $81.6 \%$ & $79.8 \%$ \\
\hline & yes & $9.2 \%$ & $10.4 \%$ & $9.8 \%$ & $13.6 \%$ & $13.5 \%$ & $13.6 \%$ & $17.2 \%$ & $18.2 \%$ & $17.7 \%$ & $21.9 \%$ & $18.4 \%$ & $20.2 \%$ \\
\hline \multirow[t]{2}{*}{ Overweight } & no & $51.3 \%$ & $67.0 \%$ & $59.0 \%$ & $43.8 \%$ & $60.7 \%$ & $52.0 \%$ & $37.9 \%$ & $55.7 \%$ & $46.6 \%$ & $32.2 \%$ & $53.0 \%$ & $42.3 \%$ \\
\hline & yes & $48.7 \%$ & $33.0 \%$ & $41.0 \%$ & $56.2 \%$ & $39.3 \%$ & $48.0 \%$ & $62.1 \%$ & $44.3 \%$ & $53.4 \%$ & $67.8 \%$ & $47.0 \%$ & $57.7 \%$ \\
\hline \multirow[t]{4}{*}{ BMI classification } & underweight & $1.1 \%$ & $5.1 \%$ & $3.1 \%$ & $0.9 \%$ & $3.7 \%$ & $2.3 \%$ & $0.8 \%$ & $3.4 \%$ & $2.1 \%$ & $0.5 \%$ & $3.0 \%$ & $1.7 \%$ \\
\hline & normal & $50.1 \%$ & $61.9 \%$ & $55.9 \%$ & $42.9 \%$ & $57.0 \%$ & $49.8 \%$ & $37.2 \%$ & $52.2 \%$ & $44.5 \%$ & $31.7 \%$ & $50.0 \%$ & $40.6 \%$ \\
\hline & overweight & $39.5 \%$ & $22.6 \%$ & $31.2 \%$ & $42.6 \%$ & $25.7 \%$ & $34.4 \%$ & $44.8 \%$ & $26.2 \%$ & $35.7 \%$ & $45.9 \%$ & $28.6 \%$ & $37.5 \%$ \\
\hline & obese & $9.2 \%$ & $10.4 \%$ & $9.8 \%$ & $13.6 \%$ & $13.5 \%$ & $13.6 \%$ & $17.2 \%$ & $18.2 \%$ & $17.7 \%$ & $21.9 \%$ & $18.4 \%$ & $20.2 \%$ \\
\hline \multirow[t]{3}{*}{ Years of education } & $0-8$ & $17.8 \%$ & $17.9 \%$ & $17.9 \%$ & $13.8 \%$ & $13.2 \%$ & $13.5 \%$ & $10.0 \%$ & $8.3 \%$ & $9.2 \%$ & $6.7 \%$ & $5.4 \%$ & $6.1 \%$ \\
\hline & $9-11$ & $65.8 \%$ & $70.2 \%$ & $68.0 \%$ & $67.1 \%$ & $71.2 \%$ & $69.1 \%$ & $67.6 \%$ & $72.1 \%$ & $69.8 \%$ & $45.6 \%$ & $44.0 \%$ & $44.8 \%$ \\
\hline & over 12 & $16.4 \%$ & $11.9 \%$ & $14.2 \%$ & $19.2 \%$ & $15.6 \%$ & $17.4 \%$ & $22.4 \%$ & $19.6 \%$ & $21.0 \%$ & $47.7 \%$ & $50.6 \%$ & $49.1 \%$ \\
\hline
\end{tabular}


Table A1.2. Canada - Canadian National Population Health Survey 1995 and Canadian Community Health Survey 2001-2005

\begin{tabular}{|c|c|c|c|c|c|c|c|c|c|c|c|c|c|}
\hline \multirow{2}{*}{ Canada } & & \multicolumn{3}{|c|}{1995} & \multicolumn{3}{|c|}{2001} & \multicolumn{3}{|c|}{2003} & \multicolumn{3}{|c|}{2005} \\
\hline & & Men & Women & Total & Men & Women & Total & Men & Women & Total & Men & Women & Total \\
\hline Total frequency & & 5009 & 5560 & 10569 & 35044 & 36852 & 71896 & 33154 & 34911 & 68065 & 33471 & 35495 & 68966 \\
\hline \multirow[t]{8}{*}{ Age group } & $25-39$ & $13.9 \%$ & $12.6 \%$ & $13.2 \%$ & $12.0 \%$ & $11.5 \%$ & $11.8 \%$ & $12.0 \%$ & $11.4 \%$ & $11.7 \%$ & $11.8 \%$ & $11.6 \%$ & $11.7 \%$ \\
\hline & $30-34$ & $16.3 \%$ & $17.5 \%$ & $16.9 \%$ & $13.3 \%$ & $12.5 \%$ & $12.9 \%$ & $11.9 \%$ & $12.0 \%$ & $12.0 \%$ & $11.7 \%$ & $11.8 \%$ & $11.7 \%$ \\
\hline & $35-39$ & $17.1 \%$ & $16.4 \%$ & $16.8 \%$ & $15.6 \%$ & $15.9 \%$ & $15.7 \%$ & $15.0 \%$ & $14.8 \%$ & $14.9 \%$ & $13.3 \%$ & $13.1 \%$ & $13.2 \%$ \\
\hline & $40-44$ & $14.8 \%$ & $14.7 \%$ & $14.7 \%$ & $16.5 \%$ & $16.5 \%$ & $16.5 \%$ & $16.6 \%$ & $16.4 \%$ & $16.5 \%$ & $16.4 \%$ & $16.0 \%$ & $16.2 \%$ \\
\hline & $45-49$ & $13.2 \%$ & $12.0 \%$ & $12.6 \%$ & $14.0 \%$ & $14.7 \%$ & $14.4 \%$ & $13.6 \%$ & $14.2 \%$ & $13.9 \%$ & $14.3 \%$ & $14.9 \%$ & $14.6 \%$ \\
\hline & $50-54$ & $10.2 \%$ & $9.9 \%$ & $10.0 \%$ & $12.2 \%$ & $12.4 \%$ & $12.3 \%$ & $12.4 \%$ & $12.8 \%$ & $12.6 \%$ & $12.5 \%$ & $13.3 \%$ & $12.9 \%$ \\
\hline & $55-59$ & $7.7 \%$ & $8.8 \%$ & $8.2 \%$ & $9.4 \%$ & $9.2 \%$ & $9.3 \%$ & $10.6 \%$ & $10.6 \%$ & $10.6 \%$ & $11.2 \%$ & $10.9 \%$ & $11.1 \%$ \\
\hline & $60-64$ & $7.0 \%$ & $8.1 \%$ & $7.5 \%$ & $7.0 \%$ & $7.4 \%$ & $7.2 \%$ & $7.8 \%$ & $7.8 \%$ & $7.8 \%$ & $8.8 \%$ & $8.4 \%$ & $8.6 \%$ \\
\hline \multirow{5}{*}{ Equivalized income } & upper & $19.9 \%$ & $16.5 \%$ & $18.2 \%$ & $37.7 \%$ & $31.8 \%$ & $34.8 \%$ & $45.0 \%$ & $37.7 \%$ & $41.5 \%$ & $54.2 \%$ & $47.6 \%$ & $51.0 \%$ \\
\hline & upper middle & $41.1 \%$ & $37.9 \%$ & $39.5 \%$ & $37.1 \%$ & $36.6 \%$ & $36.8 \%$ & $34.2 \%$ & $35.9 \%$ & $35.0 \%$ & $26.0 \%$ & $27.1 \%$ & $26.6 \%$ \\
\hline & middle & $25.6 \%$ & $28.3 \%$ & $26.9 \%$ & $17.1 \%$ & $20.2 \%$ & $18.6 \%$ & $14.6 \%$ & $17.7 \%$ & $16.1 \%$ & $12.9 \%$ & $15.9 \%$ & $14.4 \%$ \\
\hline & lower middle & $8.8 \%$ & $11.4 \%$ & $10.1 \%$ & $4.8 \%$ & $7.3 \%$ & $6.0 \%$ & $3.8 \%$ & $5.6 \%$ & $4.7 \%$ & $3.0 \%$ & $4.1 \%$ & $3.5 \%$ \\
\hline & lower & $4.7 \%$ & $5.9 \%$ & $5.3 \%$ & $3.3 \%$ & $4.1 \%$ & $3.7 \%$ & $2.4 \%$ & $3.0 \%$ & $2.7 \%$ & $3.9 \%$ & $5.3 \%$ & $4.5 \%$ \\
\hline \multirow[t]{2}{*}{ Minority } & no & & & & $86.0 \%$ & $85.9 \%$ & $86.0 \%$ & $84.3 \%$ & $85.3 \%$ & $84.8 \%$ & $83.6 \%$ & $84.0 \%$ & $83.8 \%$ \\
\hline & yes & & & & $14.0 \%$ & $14.1 \%$ & $14.0 \%$ & $15.7 \%$ & $14.7 \%$ & $15.2 \%$ & $16.4 \%$ & $16.0 \%$ & $16.2 \%$ \\
\hline \multirow[t]{2}{*}{ Obese } & no & $85.9 \%$ & $86.1 \%$ & $86.0 \%$ & $82.5 \%$ & $84.8 \%$ & $83.6 \%$ & $82.1 \%$ & $84.2 \%$ & $83.1 \%$ & $81.2 \%$ & $83.8 \%$ & $82.5 \%$ \\
\hline & yes & $14.1 \%$ & $13.9 \%$ & $14.0 \%$ & $17.5 \%$ & $15.2 \%$ & $16.4 \%$ & $17.9 \%$ & $15.8 \%$ & $16.9 \%$ & $18.8 \%$ & $16.2 \%$ & $17.5 \%$ \\
\hline \multirow[t]{2}{*}{ Overweight } & no & $39.0 \%$ & $59.2 \%$ & $49.0 \%$ & $40.4 \%$ & $57.4 \%$ & $48.7 \%$ & $38.5 \%$ & $57.0 \%$ & $47.5 \%$ & $37.7 \%$ & $56.4 \%$ & $46.7 \%$ \\
\hline & yes & $61.0 \%$ & $40.8 \%$ & $51.0 \%$ & $59.6 \%$ & $42.6 \%$ & $51.3 \%$ & $61.5 \%$ & $43.0 \%$ & $52.5 \%$ & $62.3 \%$ & $43.6 \%$ & $53.3 \%$ \\
\hline \multirow[t]{4}{*}{ BMI classification } & underweight & $0.5 \%$ & $2.6 \%$ & $1.5 \%$ & $0.9 \%$ & $3.4 \%$ & $2.1 \%$ & $0.7 \%$ & $3.1 \%$ & $1.9 \%$ & $0.7 \%$ & $3.5 \%$ & $2.0 \%$ \\
\hline & normal & $38.5 \%$ & $56.6 \%$ & $47.4 \%$ & $39.5 \%$ & $53.9 \%$ & $46.6 \%$ & $37.8 \%$ & $54.0 \%$ & $45.6 \%$ & $37.1 \%$ & $52.9 \%$ & $44.7 \%$ \\
\hline & overweight & $46.9 \%$ & $27.0 \%$ & $37.1 \%$ & $42.1 \%$ & $27.5 \%$ & $34.9 \%$ & $43.6 \%$ & $27.1 \%$ & $35.6 \%$ & $43.5 \%$ & $27.5 \%$ & $35.7 \%$ \\
\hline & obese & $14.1 \%$ & $13.9 \%$ & $14.0 \%$ & $17.5 \%$ & $15.2 \%$ & $16.4 \%$ & $17.9 \%$ & $15.8 \%$ & $16.9 \%$ & $18.8 \%$ & $16.2 \%$ & $17.5 \%$ \\
\hline \multirow[t]{4}{*}{ Years of education } & 8 & $21.6 \%$ & $21.1 \%$ & $21.4 \%$ & $18.1 \%$ & $16.8 \%$ & $17.4 \%$ & $14.1 \%$ & $13.3 \%$ & $13.7 \%$ & $12.4 \%$ & $10.7 \%$ & $11.6 \%$ \\
\hline & 12 & $14.9 \%$ & $18.4 \%$ & $16.6 \%$ & $18.2 \%$ & $21.3 \%$ & $19.7 \%$ & $18.0 \%$ & $19.6 \%$ & $18.7 \%$ & $14.8 \%$ & $15.8 \%$ & $15.3 \%$ \\
\hline & 14 & $23.7 \%$ & $25.0 \%$ & $24.3 \%$ & $6.9 \%$ & $7.3 \%$ & $7.1 \%$ & $6.3 \%$ & $6.6 \%$ & $6.5 \%$ & $7.1 \%$ & $6.7 \%$ & $6.9 \%$ \\
\hline & 17 & $39.8 \%$ & $35.5 \%$ & $37.7 \%$ & $56.9 \%$ & $54.6 \%$ & $55.8 \%$ & $61.6 \%$ & $60.5 \%$ & $61.1 \%$ & $65.7 \%$ & $66.8 \%$ & $66.3 \%$ \\
\hline
\end{tabular}


Table A1.3. Korea - Korean National Health and Examination Survey

\begin{tabular}{|c|c|c|c|c|c|c|c|c|c|c|}
\hline \multirow{2}{*}{ Korea } & & \multicolumn{3}{|c|}{1998} & \multicolumn{3}{|c|}{2001} & \multicolumn{3}{|c|}{2005} \\
\hline & & Men & Women & Total & Men & Women & Total & Men & Women & Total \\
\hline Total frequency & & 2941 & 3396 & 6337 & 2179 & 2706 & 4885 & 1822 & 2398 & 4220 \\
\hline \multirow[t]{8}{*}{ Age group } & $25-39$ & $13.6 \%$ & $14.4 \%$ & $14.0 \%$ & $11.7 \%$ & $12.7 \%$ & $12.3 \%$ & $8.3 \%$ & $9.0 \%$ & $8.7 \%$ \\
\hline & $30-34$ & $15.4 \%$ & $15.4 \%$ & $15.4 \%$ & $15.4 \%$ & $16.0 \%$ & $15.7 \%$ & $13.7 \%$ & $15.1 \%$ & $14.5 \%$ \\
\hline & $35-39$ & $16.0 \%$ & $15.3 \%$ & $15.6 \%$ & $16.3 \%$ & $16.6 \%$ & $16.5 \%$ & $13.3 \%$ & $14.9 \%$ & $14.2 \%$ \\
\hline & $40-44$ & $15.3 \%$ & $14.3 \%$ & $14.7 \%$ & $16.4 \%$ & $16.6 \%$ & $16.5 \%$ & $15.3 \%$ & $16.3 \%$ & $15.9 \%$ \\
\hline & $45-49$ & $11.1 \%$ & $10.9 \%$ & $11.0 \%$ & $13.3 \%$ & $11.7 \%$ & $12.4 \%$ & $17.0 \%$ & $14.3 \%$ & $15.5 \%$ \\
\hline & $50-54$ & $9.9 \%$ & $9.6 \%$ & $9.7 \%$ & $8.6 \%$ & $9.4 \%$ & $9.0 \%$ & $10.4 \%$ & $11.2 \%$ & $10.8 \%$ \\
\hline & $55-59$ & $9.6 \%$ & $10.6 \%$ & $10.1 \%$ & $10.1 \%$ & $8.4 \%$ & $9.1 \%$ & $11.9 \%$ & $9.7 \%$ & $10.6 \%$ \\
\hline & $60-64$ & $9.1 \%$ & $9.6 \%$ & $9.4 \%$ & $8.2 \%$ & $8.6 \%$ & $8.4 \%$ & $10.2 \%$ & $9.4 \%$ & $9.7 \%$ \\
\hline \multirow{5}{*}{ Equivalized income } & upper & $20.5 \%$ & $25.6 \%$ & $23.3 \%$ & $22.7 \%$ & $28.7 \%$ & $26.0 \%$ & $22.7 \%$ & $27.4 \%$ & $25.4 \%$ \\
\hline & upper middle & $21.8 \%$ & $21.6 \%$ & $21.7 \%$ & $19.4 \%$ & $18.7 \%$ & $19.0 \%$ & $21.5 \%$ & $19.9 \%$ & $20.6 \%$ \\
\hline & middle & $21.9 \%$ & $19.1 \%$ & $20.4 \%$ & $22.9 \%$ & $19.7 \%$ & $21.1 \%$ & $20.9 \%$ & $18.6 \%$ & $19.6 \%$ \\
\hline & lower middle & $20.4 \%$ & $18.6 \%$ & $19.4 \%$ & $20.3 \%$ & $18.7 \%$ & $19.4 \%$ & $20.4 \%$ & $18.7 \%$ & $19.5 \%$ \\
\hline & lower & $15.4 \%$ & $15.0 \%$ & $15.2 \%$ & $14.7 \%$ & $14.3 \%$ & $14.5 \%$ & $14.4 \%$ & $15.4 \%$ & $15.0 \%$ \\
\hline \multirow[t]{2}{*}{ Obese } & no & $98.2 \%$ & $96.7 \%$ & $97.4 \%$ & $97.4 \%$ & $96.5 \%$ & $96.9 \%$ & $96.8 \%$ & $96.1 \%$ & $96.4 \%$ \\
\hline & yes & $1.8 \%$ & $3.3 \%$ & $2.6 \%$ & $2.6 \%$ & $3.5 \%$ & $3.1 \%$ & $3.2 \%$ & $3.9 \%$ & $3.6 \%$ \\
\hline \multirow[t]{2}{*}{ Overweight } & no & $72.2 \%$ & $70.8 \%$ & $71.4 \%$ & $65.5 \%$ & $70.9 \%$ & $68.5 \%$ & $61.6 \%$ & $70.4 \%$ & $66.6 \%$ \\
\hline & yes & $27.8 \%$ & $29.2 \%$ & $28.6 \%$ & $34.5 \%$ & $29.1 \%$ & $31.5 \%$ & $38.4 \%$ & $29.6 \%$ & $33.4 \%$ \\
\hline \multirow[t]{4}{*}{ BMI classification } & underweight & $3.2 \%$ & $3.8 \%$ & $3.5 \%$ & $2.2 \%$ & $4.7 \%$ & $3.6 \%$ & $2.7 \%$ & $4.1 \%$ & $3.5 \%$ \\
\hline & normal & $68.9 \%$ & $67.0 \%$ & $67.9 \%$ & $63.3 \%$ & $66.1 \%$ & $64.9 \%$ & $58.9 \%$ & $66.2 \%$ & $63.1 \%$ \\
\hline & overweight & $26.1 \%$ & $25.9 \%$ & $26.0 \%$ & $31.9 \%$ & $25.6 \%$ & $28.4 \%$ & $35.2 \%$ & $25.8 \%$ & $29.8 \%$ \\
\hline & obese & $1.8 \%$ & $3.3 \%$ & $2.6 \%$ & $2.6 \%$ & $3.5 \%$ & $3.1 \%$ & $3.2 \%$ & $3.9 \%$ & $3.6 \%$ \\
\hline \multirow[t]{5}{*}{ Years of education } & 6 & $16.8 \%$ & $31.5 \%$ & $24.7 \%$ & $10.5 \%$ & $21.0 \%$ & $16.3 \%$ & $9.9 \%$ & $20.3 \%$ & $15.8 \%$ \\
\hline & 9 & $15.5 \%$ & $17.5 \%$ & $16.6 \%$ & $14.0 \%$ & $15.4 \%$ & $14.8 \%$ & $12.6 \%$ & $14.1 \%$ & $13.4 \%$ \\
\hline & 12 & $40.2 \%$ & $35.5 \%$ & $37.7 \%$ & $39.0 \%$ & $41.9 \%$ & $40.6 \%$ & $37.7 \%$ & $39.8 \%$ & $38.9 \%$ \\
\hline & 16 & $24.2 \%$ & $14.7 \%$ & $19.1 \%$ & $31.3 \%$ & $20.7 \%$ & $25.4 \%$ & $35.0 \%$ & $24.1 \%$ & $28.8 \%$ \\
\hline & 17 & $3.2 \%$ & $0.8 \%$ & $1.9 \%$ & $5.2 \%$ & $1.1 \%$ & $2.9 \%$ & $4.8 \%$ & $1.8 \%$ & $3.1 \%$ \\
\hline
\end{tabular}


Table A1.4. England - Health Survey for England

\begin{tabular}{|c|c|c|c|c|c|c|c|c|c|c|c|c|c|c|c|c|c|c|c|c|c|c|c|c|c|}
\hline \multirow{2}{*}{ England } & & \multicolumn{3}{|c|}{1991} & \multicolumn{3}{|c|}{1992} & \multicolumn{3}{|c|}{1993} & \multicolumn{3}{|c|}{1994} & \multicolumn{3}{|c|}{1995} & \multicolumn{3}{|c|}{1996} & \multicolumn{3}{|c|}{1997} & \multicolumn{3}{|c|}{1998} \\
\hline & & Men & Women & Total & Men & Women & Total & Men & Women & Total & Men & Women & Total & Men & Women & Total & Men & Women & Total & Men & Women & Total & Men & Women & n Total \\
\hline Total Frequency & & 937 & 1046 & 1983 & 1162 & 1242 & 2404 & 5000 & 5364 & 10364 & 4557 & 5073 & 9630 & 4536 & 5108 & 9644 & 4734 & 5303 & 10037 & 2514 & 2867 & 5381 & 4484 & 5221 & 9705 \\
\hline \multirow[t]{8}{*}{ Age group } & $25-39$ & $14.8 \%$ & $13.4 \%$ & $14.1 \%$ & $15.6 \%$ & $15.3 \%$ & $15.4 \%$ & $14.2 \%$ & $14.1 \%$ & $14.2 \%$ & $14.0 \%$ & $14.3 \%$ & $14.1 \%$ & $12.1 \%$ & $13.6 \%$ & $12.9 \%$ & $12.1 \%$ & $12.7 \%$ & $12.5 \%$ & $13.1 \%$ & $12.6 \%$ & $12.8 \%$ & $12.3 \%$ & $12.4 \%$ & $12.4 \%$ \\
\hline & $30-34$ & $14.6 \%$ & $15.5 \%$ & $15.1 \%$ & $12.0 \%$ & $12.9 \%$ & $12.5 \%$ & $14.3 \%$ & $14.6 \%$ & $14.4 \%$ & $15.3 \%$ & $15.0 \%$ & $15.1 \%$ & $15.6 \%$ & $15.2 \%$ & $15.4 \%$ & $14.3 \%$ & $14.7 \%$ & $14.6 \%$ & $13.9 \%$ & $14.9 \%$ & $14.4 \%$ & $14.6 \%$ & $14.4 \%$ & $14.5 \%$ \\
\hline & $35-39$ & $13.1 \%$ & $12.4 \%$ & $12.8 \%$ & $13.6 \%$ & $14.1 \%$ & $13.9 \%$ & $13.1 \%$ & $13.9 \%$ & $13.5 \%$ & $15.1 \%$ & $14.7 \%$ & $14.9 \%$ & $15.1 \%$ & $13.6 \%$ & $14.3 \%$ & $13.9 \%$ & $14.7 \%$ & $14.3 \%$ & $13.9 \%$ & $13.2 \%$ & $13.5 \%$ & $14.4 \%$ & $14.7 \%$ & $14.6 \%$ \\
\hline & $40-44$ & $14.3 \%$ & $15.2 \%$ & $14.8 \%$ & $14.3 \%$ & $14.2 \%$ & $14.2 \%$ & $12.9 \%$ & $13.2 \%$ & $13.0 \%$ & $12.4 \%$ & $12.8 \%$ & $12.6 \%$ & $13.0 \%$ & $12.9 \%$ & $13.0 \%$ & $13.9 \%$ & $12.8 \%$ & $13.4 \%$ & $13.6 \%$ & $13.5 \%$ & $13.5 \%$ & $12.3 \%$ & $12.4 \%$ & $12.4 \%$ \\
\hline & $45-49$ & $12.3 \%$ & $11.5 \%$ & $11.9 \%$ & $14.0 \%$ & $12.0 \%$ & $13.0 \%$ & $14.3 \%$ & $13.6 \%$ & $13.9 \%$ & $12.7 \%$ & $13.5 \%$ & $13.1 \%$ & $12.4 \%$ & $12.9 \%$ & $12.7 \%$ & $14.1 \%$ & $13.7 \%$ & $13.9 \%$ & $13.6 \%$ & $13.9 \%$ & $13.8 \%$ & $13.4 \%$ & $12.6 \%$ & $13.0 \%$ \\
\hline & $50-54$ & $10.0 \%$ & $10.5 \%$ & $10.3 \%$ & $10.8 \%$ & $10.8 \%$ & $10.8 \%$ & $10.6 \%$ & $10.8 \%$ & $10.7 \%$ & $10.4 \%$ & $10.3 \%$ & $10.3 \%$ & $11.4 \%$ & $11.6 \%$ & $11.6 \%$ & $12.0 \%$ & $12.1 \%$ & $12.0 \%$ & $12.1 \%$ & $12.6 \%$ & $12.4 \%$ & $12.8 \%$ & $13.4 \%$ & $13.1 \%$ \\
\hline & $55-59$ & $10.1 \%$ & $10.5 \%$ & $10.3 \%$ & $9.2 \%$ & $9.4 \%$ & $9.3 \%$ & $10.7 \%$ & $9.9 \%$ & $10.3 \%$ & $9.8 \%$ & $9.5 \%$ & $9.7 \%$ & $10.2 \%$ & $10.5 \%$ & $10.4 \%$ & $9.6 \%$ & $9.4 \%$ & $9.5 \%$ & $10.1 \%$ & $9.8 \%$ & $10.0 \%$ & $9.7 \%$ & $9.8 \%$ & $9.8 \%$ \\
\hline & $60-64$ & $10.7 \%$ & $11.0 \%$ & $10.8 \%$ & $10.5 \%$ & $11.4 \%$ & $10.9 \%$ & $9.9 \%$ & $10.0 \%$ & $9.9 \%$ & $10.4 \%$ & $9.9 \%$ & $10.1 \%$ & $10.1 \%$ & $9.6 \%$ & $9.8 \%$ & $10.1 \%$ & $9.8 \%$ & $9.9 \%$ & $9.7 \%$ & $9.5 \%$ & $9.6 \%$ & $10.4 \%$ & $10.3 \%$ & $10.3 \%$ \\
\hline \multirow[t]{5}{*}{ Socioeconomic status } & upper & $7.6 \%$ & $1.8 \%$ & $4.5 \%$ & $8.6 \%$ & $1.8 \%$ & $5.1 \%$ & $10.0 \%$ & $2.4 \%$ & $6.0 \%$ & $8.3 \%$ & $2.3 \%$ & $5.1 \%$ & $8.4 \%$ & $1.9 \%$ & $5.0 \%$ & $7.5 \%$ & $2.2 \%$ & $4.7 \%$ & $8.0 \%$ & $2.3 \%$ & $5.0 \%$ & $7.2 \%$ & $2.4 \%$ & $4.7 \%$ \\
\hline & upper middle & $32.9 \%$ & $26.6 \%$ & $29.6 \%$ & $30.3 \%$ & $25.7 \%$ & $27.9 \%$ & $30.3 \%$ & $26.6 \%$ & $28.4 \%$ & $29.6 \%$ & $26.3 \%$ & $27.9 \%$ & $31.1 \%$ & $25.6 \%$ & $28.2 \%$ & $32.3 \%$ & $25.9 \%$ & $29.0 \%$ & $31.3 \%$ & $25.3 \%$ & $28.1 \%$ & $31.8 \%$ & $25.6 \%$ & $28.5 \%$ \\
\hline & middle & $40.8 \%$ & $42.9 \%$ & $41.9 \%$ & $43.3 \%$ & $47.8 \%$ & $45.6 \%$ & $43.9 \%$ & $44.1 \%$ & $44.0 \%$ & $43.2 \%$ & $44.0 \%$ & $43.6 \%$ & $42.7 \%$ & $46.4 \%$ & $44.6 \%$ & $42.8 \%$ & $45.0 \%$ & $43.9 \%$ & $42.4 \%$ & $45.3 \%$ & $43.9 \%$ & $42.6 \%$ & $44.3 \%$ & $43.5 \%$ \\
\hline & lower middle & $14.3 \%$ & $18.5 \%$ & $16.5 \%$ & $13.3 \%$ & $15.8 \%$ & $14.6 \%$ & $11.7 \%$ & $18.8 \%$ & $15.4 \%$ & $13.8 \%$ & $19.8 \%$ & $17.0 \%$ & $13.1 \%$ & $19.0 \%$ & $16.2 \%$ & $12.7 \%$ & $19.7 \%$ & $16.4 \%$ & $14.7 \%$ & $19.9 \%$ & $17.5 \%$ & $13.6 \%$ & $19.7 \%$ & $16.9 \%$ \\
\hline & lower & $4.5 \%$ & $10.2 \%$ & $7.5 \%$ & $4.5 \%$ & $8.9 \%$ & $6.8 \%$ & $4.1 \%$ & $8.1 \%$ & $6.2 \%$ & $5.0 \%$ & $7.6 \%$ & $6.4 \%$ & $4.7 \%$ & $7.2 \%$ & $6.0 \%$ & $4.7 \%$ & $7.2 \%$ & $6.0 \%$ & $3.6 \%$ & $7.2 \%$ & $5.5 \%$ & $4.7 \%$ & $7.9 \%$ & $6.4 \%$ \\
\hline \multirow[t]{3}{*}{ Ethnicity } & White & $95.8 \%$ & $96.1 \%$ & $96.0 \%$ & $95.3 \%$ & $96.1 \%$ & $95.7 \%$ & $95.2 \%$ & $95.3 \%$ & $95.3 \%$ & $95.2 \%$ & $95.4 \%$ & $95.3 \%$ & $95.4 \%$ & $95.6 \%$ & $95.5 \%$ & $94.6 \%$ & $94.8 \%$ & $94.7 \%$ & $94.3 \%$ & $94.8 \%$ & $94.6 \%$ & $95.0 \%$ & $95.4 \%$ & $95.2 \%$ \\
\hline & Black & $2.0 \%$ & $2.0 \%$ & $2.0 \%$ & $1.2 \%$ & $1.7 \%$ & $1.5 \%$ & $1.8 \%$ & $2.0 \%$ & $1.9 \%$ & $1.4 \%$ & $2.1 \%$ & $1.7 \%$ & $1.3 \%$ & $1.6 \%$ & $1.5 \%$ & $1.8 \%$ & $2.2 \%$ & $2.0 \%$ & $1.7 \%$ & $1.9 \%$ & $1.8 \%$ & $2.1 \%$ & $\quad 1.9 \%$ & $2.0 \%$ \\
\hline & Asian & $2.1 \%$ & $1.9 \%$ & $2.0 \%$ & $3.5 \%$ & $2.2 \%$ & $2.8 \%$ & $3.0 \%$ & $2.7 \%$ & $2.9 \%$ & $3.4 \%$ & $2.5 \%$ & $2.9 \%$ & $3.3 \%$ & $2.8 \%$ & $3.0 \%$ & $3.6 \%$ & $3.0 \%$ & $3.3 \%$ & $4.1 \%$ & $3.3 \%$ & $3.6 \%$ & $2.9 \%$ & $2.7 \%$ & $2.8 \%$ \\
\hline \multirow[t]{2}{*}{ Obese } & no & $85.5 \%$ & $82.6 \%$ & $84.0 \%$ & $86.0 \%$ & $82.0 \%$ & $83.9 \%$ & $85.3 \%$ & $82.7 \%$ & $83.9 \%$ & $85.0 \%$ & $82.3 \%$ & $83.6 \%$ & $83.1 \%$ & $81.8 \%$ & $82.4 \%$ & $81.8 \%$ & $80.9 \%$ & $81.3 \%$ & $81.0 \%$ & $79.3 \%$ & $80.1 \%$ & $81.2 \%$ & 6 $78.3 \%$ & $79.6 \%$ \\
\hline & yes & $14.5 \%$ & $17.4 \%$ & $16.0 \%$ & $14.0 \%$ & $18.0 \%$ & $16.1 \%$ & $14.7 \%$ & $17.3 \%$ & $16.1 \%$ & $15.0 \%$ & $17.7 \%$ & $16.4 \%$ & $16.9 \%$ & $18.2 \%$ & $17.6 \%$ & $18.2 \%$ & $19.1 \%$ & $18.7 \%$ & $19.0 \%$ & $20.7 \%$ & $19.9 \%$ & $18.8 \%$ & $21.7 \%$ & $20.4 \%$ \\
\hline \multirow[t]{2}{*}{ Overweight } & no & $42.7 \%$ & $54.2 \%$ & $48.8 \%$ & $39.9 \%$ & $53.5 \%$ & $47.0 \%$ & $38.3 \%$ & $50.9 \%$ & $44.8 \%$ & $38.6 \%$ & $51.2 \%$ & $45.3 \%$ & $36.8 \%$ & $49.2 \%$ & $43.4 \%$ & $34.4 \%$ & $47.0 \%$ & $41.0 \%$ & $33.4 \%$ & $46.9 \%$ & $40.6 \%$ & $33.0 \%$ & $45.5 \%$ & $39.7 \%$ \\
\hline & yes & $57.3 \%$ & $45.8 \%$ & $51.2 \%$ & $60.1 \%$ & $46.5 \%$ & $53.0 \%$ & $61.7 \%$ & $49.1 \%$ & $55.2 \%$ & $61.4 \%$ & $48.8 \%$ & $54.7 \%$ & $63.2 \%$ & $50.8 \%$ & $56.6 \%$ & $65.6 \%$ & $53.0 \%$ & $59.0 \%$ & $66.6 \%$ & $53.1 \%$ & $59.4 \%$ & $67.0 \%$ & $54.5 \%$ & $60.3 \%$ \\
\hline \multirow[t]{4}{*}{ BMI classification } & under-weight & $1.2 \%$ & $2.0 \%$ & $1.6 \%$ & $0.9 \%$ & $2.0 \%$ & $1.5 \%$ & $0.7 \%$ & $1.4 \%$ & $1.1 \%$ & $0.6 \%$ & $1.6 \%$ & $1.1 \%$ & $0.7 \%$ & $1.4 \%$ & $1.0 \%$ & $0.6 \%$ & $1.2 \%$ & $0.9 \%$ & $0.3 \%$ & $1.5 \%$ & $0.9 \%$ & $0.6 \%$ & $1.2 \%$ & $0.9 \%$ \\
\hline & normal & $41.5 \%$ & $52.2 \%$ & $47.2 \%$ & $39.1 \%$ & $51.5 \%$ & $45.5 \%$ & $37.5 \%$ & $49.5 \%$ & $43.7 \%$ & $38.1 \%$ & $49.6 \%$ & $44.2 \%$ & $36.2 \%$ & $47.8 \%$ & $42.3 \%$ & $33.8 \%$ & $45.9 \%$ & $40.2 \%$ & $33.1 \%$ & $45.4 \%$ & $39.6 \%$ & $32.4 \%$ & $44.3 \%$ & $38.8 \%$ \\
\hline & overweight & $42.8 \%$ & $28.4 \%$ & $35.2 \%$ & $46.0 \%$ & $28.5 \%$ & $37.0 \%$ & $47.0 \%$ & $31.8 \%$ & $39.1 \%$ & $46.4 \%$ & $31.1 \%$ & $38.3 \%$ & $46.3 \%$ & $32.6 \%$ & $39.0 \%$ & $47.4 \%$ & $33.9 \%$ & $40.3 \%$ & $47.6 \%$ & $32.4 \%$ & $39.5 \%$ & $48.2 \%$ & $32.8 \%$ & $39.9 \%$ \\
\hline & obese & $14.5 \%$ & $17.4 \%$ & $16.0 \%$ & $14.0 \%$ & $18.0 \%$ & $16.1 \%$ & $14.7 \%$ & $17.3 \%$ & $16.1 \%$ & $15.0 \%$ & $17.7 \%$ & $16.4 \%$ & $16.9 \%$ & $18.2 \%$ & $17.6 \%$ & $18.2 \%$ & $19.1 \%$ & $18.7 \%$ & $19.0 \%$ & $20.7 \%$ & $19.9 \%$ & $18.8 \%$ & $21.7 \%$ & $20.4 \%$ \\
\hline \multirow[t]{7}{*}{ Years of education } & 8 & $11.4 \%$ & $12.0 \%$ & $11.7 \%$ & $10.2 \%$ & $9.3 \%$ & $9.7 \%$ & $8.5 \%$ & $8.2 \%$ & $8.3 \%$ & $7.5 \%$ & $6.8 \%$ & $7.1 \%$ & $6.7 \%$ & $5.5 \%$ & $6.1 \%$ & $5.0 \%$ & $5.2 \%$ & $5.1 \%$ & $3.7 \%$ & $4.4 \%$ & $4.1 \%$ & $2.8 \%$ & $2.8 \%$ & $2.8 \%$ \\
\hline & 9 & $30.6 \%$ & $29.3 \%$ & $29.9 \%$ & $28.4 \%$ & $29.9 \%$ & $29.2 \%$ & $27.7 \%$ & $29.2 \%$ & $28.5 \%$ & $25.2 \%$ & $27.8 \%$ & $26.5 \%$ & $27.3 \%$ & $29.1 \%$ & $28.2 \%$ & $26.8 \%$ & $26.7 \%$ & $26.7 \%$ & $26.0 \%$ & $29.1 \%$ & $27.6 \%$ & $27.8 \%$ & $27.1 \%$ & $27.4 \%$ \\
\hline & 10 & $27.2 \%$ & $26.9 \%$ & $27.0 \%$ & $28.8 \%$ & $28.8 \%$ & $28.8 \%$ & $29.4 \%$ & $27.7 \%$ & $28.5 \%$ & $31.6 \%$ & $28.4 \%$ & $29.9 \%$ & $30.6 \%$ & $29.3 \%$ & $29.9 \%$ & $31.8 \%$ & $31.4 \%$ & $31.6 \%$ & $31.5 \%$ & $30.1 \%$ & $30.7 \%$ & $32.2 \%$ & $31.8 \%$ & $32.0 \%$ \\
\hline & 11 & $7.7 \%$ & $9.3 \%$ & $8.5 \%$ & $7.0 \%$ & $9.2 \%$ & $8.1 \%$ & $7.5 \%$ & $8.7 \%$ & $8.1 \%$ & $7.5 \%$ & $10.0 \%$ & $8.8 \%$ & $8.1 \%$ & $10.0 \%$ & $9.1 \%$ & $7.5 \%$ & $10.1 \%$ & $8.8 \%$ & $7.9 \%$ & $9.4 \%$ & $8.7 \%$ & $7.5 \%$ & $9.4 \%$ & $8.5 \%$ \\
\hline & 12 & $5.1 \%$ & $10.0 \%$ & $7.7 \%$ & $6.7 \%$ & $10.0 \%$ & $8.4 \%$ & $7.2 \%$ & $9.4 \%$ & $8.3 \%$ & $7.5 \%$ & $10.2 \%$ & $8.9 \%$ & $7.5 \%$ & $10.0 \%$ & $8.8 \%$ & $7.3 \%$ & $9.3 \%$ & $8.3 \%$ & $8.5 \%$ & $10.1 \%$ & $9.4 \%$ & $7.1 \%$ & $11.0 \%$ & $9.2 \%$ \\
\hline & 13 & $5.7 \%$ & $6.8 \%$ & $6.3 \%$ & $7.7 \%$ & $6.0 \%$ & $6.8 \%$ & $6.9 \%$ & $8.9 \%$ & $8.0 \%$ & $8.3 \%$ & $8.2 \%$ & $8.2 \%$ & $19.8 \%$ & $16.0 \%$ & $17.8 \%$ & $21.4 \%$ & $17.3 \%$ & $19.2 \%$ & $8.5 \%$ & $7.1 \%$ & $7.7 \%$ & $8.4 \%$ & $8.0 \%$ & $8.2 \%$ \\
\hline & 15 & $12.3 \%$ & $5.8 \%$ & $8.9 \%$ & $11.3 \%$ & $6.8 \%$ & $8.9 \%$ & $12.9 \%$ & $7.8 \%$ & $10.3 \%$ & $12.5 \%$ & $8.7 \%$ & $10.5 \%$ & $0.1 \%$ & $0.1 \%$ & $0.1 \%$ & $0.2 \%$ & $0.1 \%$ & $0.1 \%$ & $14.0 \%$ & $9.8 \%$ & $11.8 \%$ & $14.1 \%$ & $9.8 \%$ & $11.8 \%$ \\
\hline
\end{tabular}


Table A1.4. England - Health Survey for England (cont.)

\begin{tabular}{|c|c|c|c|c|c|c|c|c|c|c|c|c|c|c|c|c|c|c|c|c|c|c|}
\hline \multirow{2}{*}{ England } & & \multicolumn{3}{|c|}{1999} & \multicolumn{3}{|c|}{2000} & \multicolumn{3}{|c|}{2001} & \multicolumn{3}{|c|}{2002} & \multicolumn{3}{|c|}{2003} & \multicolumn{3}{|c|}{2004} & \multicolumn{3}{|c|}{2005} \\
\hline & & Men & Women & Total & Men & Women & Total & Men & Women & Total & Men & Women & Total & Men & Women & Total & Men & Women & Total & Men & Women & Total \\
\hline Total Frequency & & 2190 & 2494 & 4684 & 2186 & 2520 & 4706 & 4261 & 4976 & 9237 & 1971 & 2531 & 4502 & 4025 & 4745 & 8770 & 3027 & 3689 & 6716 & 1950 & 2342 & 4292 \\
\hline \multirow[t]{8}{*}{ Age group } & 25-39 & $11.4 \%$ & $10.2 \%$ & $10.7 \%$ & $11.0 \%$ & $11.5 \%$ & $11.3 \%$ & $10.4 \%$ & $10.7 \%$ & $10.6 \%$ & $10.2 \%$ & $11.7 \%$ & $11.0 \%$ & $9.6 \%$ & $9.3 \%$ & $9.4 \%$ & $11.5 \%$ & $12.4 \%$ & $12.0 \%$ & $8.8 \%$ & $10.0 \%$ & $9.5 \%$ \\
\hline & $30-34$ & $13.8 \%$ & $14.8 \%$ & $14.3 \%$ & $15.2 \%$ & $14.4 \%$ & $14.7 \%$ & $13.4 \%$ & $12.7 \%$ & $13.0 \%$ & $12.3 \%$ & $14.0 \%$ & $13.3 \%$ & $12.8 \%$ & $12.3 \%$ & $12.6 \%$ & $15.8 \%$ & $13.6 \%$ & $14.6 \%$ & $13.5 \%$ & $11.3 \%$ & $12.3 \%$ \\
\hline & $35-39$ & $15.2 \%$ & $15.4 \%$ & $15.3 \%$ & $15.0 \%$ & $15.8 \%$ & $15.4 \%$ & $14.8 \%$ & $15.6 \%$ & $15.2 \%$ & $15.4 \%$ & $17.8 \%$ & $16.7 \%$ & $13.9 \%$ & $15.1 \%$ & $14.5 \%$ & $15.2 \%$ & $15.3 \%$ & $15.3 \%$ & $12.9 \%$ & $12.9 \%$ & $12.9 \%$ \\
\hline & $40-44$ & $12.4 \%$ & $13.8 \%$ & $13.2 \%$ & $13.8 \%$ & $14.1 \%$ & $14.0 \%$ & $13.3 \%$ & $13.8 \%$ & $13.6 \%$ & $15.6 \%$ & $13.4 \%$ & $14.4 \%$ & $14.3 \%$ & $14.7 \%$ & $14.5 \%$ & $14.9 \%$ & $15.7 \%$ & $15.3 \%$ & $11.9 \%$ & $14.9 \%$ & $13.6 \%$ \\
\hline & $45-49$ & $12.9 \%$ & $12.1 \%$ & $12.4 \%$ & $10.7 \%$ & $11.9 \%$ & $11.3 \%$ & $12.1 \%$ & $12.3 \%$ & $12.2 \%$ & $11.6 \%$ & $11.1 \%$ & $11.3 \%$ & $11.9 \%$ & $11.9 \%$ & $11.9 \%$ & $11.7 \%$ & $12.4 \%$ & $12.1 \%$ & $13.6 \%$ & $14.1 \%$ & $13.9 \%$ \\
\hline & $50-54$ & $13.2 \%$ & $15.2 \%$ & $14.2 \%$ & $12.9 \%$ & $12.7 \%$ & $12.8 \%$ & $13.8 \%$ & $13.9 \%$ & $13.8 \%$ & $12.2 \%$ & $11.8 \%$ & $12.0 \%$ & $12.6 \%$ & $11.7 \%$ & $12.1 \%$ & $11.3 \%$ & $10.8 \%$ & $11.0 \%$ & $13.4 \%$ & $11.9 \%$ & $12.6 \%$ \\
\hline & $55-59$ & $11.5 \%$ & $8.9 \%$ & $10.1 \%$ & $11.6 \%$ & $10.7 \%$ & $11.1 \%$ & $12.1 \%$ & $11.6 \%$ & $11.8 \%$ & $12.1 \%$ & $11.6 \%$ & $11.8 \%$ & $13.9 \%$ & $14.2 \%$ & $14.1 \%$ & $9.8 \%$ & $9.8 \%$ & $9.8 \%$ & $13.6 \%$ & $13.3 \%$ & $13.4 \%$ \\
\hline & $60-64$ & $9.7 \%$ & $9.6 \%$ & $9.7 \%$ & $9.8 \%$ & $9.0 \%$ & $9.4 \%$ & $10.1 \%$ & $9.4 \%$ & $9.7 \%$ & $10.5 \%$ & $8.7 \%$ & $9.5 \%$ & $10.9 \%$ & $10.9 \%$ & $10.9 \%$ & $9.8 \%$ & $10.0 \%$ & $9.9 \%$ & $12.2 \%$ & $11.6 \%$ & $11.8 \%$ \\
\hline \multirow[t]{5}{*}{ Socioeconomic status } & upper & $9.4 \%$ & $2.1 \%$ & $5.5 \%$ & $7.8 \%$ & $2.1 \%$ & $4.8 \%$ & $7.8 \%$ & $2.7 \%$ & $5.0 \%$ & $9.1 \%$ & $3.6 \%$ & $6.0 \%$ & $8.4 \%$ & $3.3 \%$ & $5.6 \%$ & $7.4 \%$ & $4.1 \%$ & $5.6 \%$ & $8.6 \%$ & $3.5 \%$ & $5.8 \%$ \\
\hline & upper middle & $31.6 \%$ & $26.9 \%$ & $29.1 \%$ & $32.4 \%$ & $30.1 \%$ & $31.2 \%$ & $33.2 \%$ & $29.8 \%$ & $31.4 \%$ & $32.1 \%$ & $30.6 \%$ & $31.3 \%$ & $33.6 \%$ & $32.5 \%$ & $33.0 \%$ & $32.0 \%$ & $31.6 \%$ & $31.8 \%$ & $35.5 \%$ & $33.7 \%$ & $34.6 \%$ \\
\hline & middle & $43.6 \%$ & $45.9 \%$ & $44.8 \%$ & $42.6 \%$ & $43.1 \%$ & $42.9 \%$ & $41.4 \%$ & $42.1 \%$ & $41.8 \%$ & $41.7 \%$ & $41.8 \%$ & $41.8 \%$ & $41.0 \%$ & $39.7 \%$ & $40.3 \%$ & $40.2 \%$ & $37.6 \%$ & $38.8 \%$ & $39.1 \%$ & $40.3 \%$ & $39.7 \%$ \\
\hline & lower middle & $12.4 \%$ & $18.6 \%$ & $15.7 \%$ & $13.2 \%$ & $17.9 \%$ & $15.7 \%$ & $13.4 \%$ & $19.7 \%$ & $16.8 \%$ & $13.5 \%$ & $19.0 \%$ & $16.6 \%$ & $13.3 \%$ & $19.2 \%$ & $16.5 \%$ & $16.4 \%$ & $21.6 \%$ & $19.3 \%$ & $12.4 \%$ & $17.5 \%$ & $15.2 \%$ \\
\hline & lower & $3.0 \%$ & $6.5 \%$ & $4.8 \%$ & $4.0 \%$ & $6.7 \%$ & $5.5 \%$ & $4.2 \%$ & $5.7 \%$ & $5.0 \%$ & $3.5 \%$ & $4.9 \%$ & $4.3 \%$ & $3.7 \%$ & $5.2 \%$ & $4.5 \%$ & $4.0 \%$ & $5.0 \%$ & $4.5 \%$ & $4.4 \%$ & $5.0 \%$ & $4.7 \%$ \\
\hline \multirow[t]{3}{*}{ Ethnicity } & White & $94.2 \%$ & $94.9 \%$ & $94.6 \%$ & $94.2 \%$ & $94.4 \%$ & $94.3 \%$ & $94.8 \%$ & $95.0 \%$ & $94.9 \%$ & $94.1 \%$ & $94.1 \%$ & $94.1 \%$ & $93.6 \%$ & $94.0 \%$ & $93.8 \%$ & $58.3 \%$ & $60.9 \%$ & $59.8 \%$ & $93.6 \%$ & $93.9 \%$ & $93.8 \%$ \\
\hline & Black & $1.6 \%$ & $1.7 \%$ & $1.7 \%$ & $1.4 \%$ & $1.7 \%$ & $1.6 \%$ & $1.4 \%$ & $1.8 \%$ & $1.6 \%$ & $1.4 \%$ & $2.1 \%$ & $1.8 \%$ & $1.9 \%$ & $2.0 \%$ & $2.0 \%$ & $13.2 \%$ & $14.3 \%$ & $13.8 \%$ & $1.1 \%$ & $1.8 \%$ & $1.5 \%$ \\
\hline & Asian & $4.1 \%$ & $3.4 \%$ & $3.8 \%$ & $4.4 \%$ & $3.9 \%$ & $4.1 \%$ & $3.8 \%$ & $3.2 \%$ & $3.5 \%$ & $4.5 \%$ & $3.9 \%$ & $4.1 \%$ & $4.5 \%$ & $4.0 \%$ & $4.2 \%$ & $28.4 \%$ & $24.8 \%$ & $26.4 \%$ & $5.2 \%$ & $4.3 \%$ & $4.7 \%$ \\
\hline \multirow[t]{2}{*}{ Obese } & no & $79.7 \%$ & $78.2 \%$ & $78.9 \%$ & $77.3 \%$ & $78.8 \%$ & $78.1 \%$ & $77.2 \%$ & $75.2 \%$ & $76.2 \%$ & $76.0 \%$ & $76.0 \%$ & $76.0 \%$ & $75.7 \%$ & $76.2 \%$ & $76.0 \%$ & $78.4 \%$ & $74.2 \%$ & $76.1 \%$ & $74.2 \%$ & $74.5 \%$ & $74.3 \%$ \\
\hline & yes & $20.3 \%$ & $21.8 \%$ & $21.1 \%$ & $22.7 \%$ & $21.2 \%$ & $21.9 \%$ & $22.8 \%$ & $24.8 \%$ & $23.8 \%$ & $24.0 \%$ & $24.0 \%$ & $24.0 \%$ & $24.3 \%$ & $23.8 \%$ & $24.0 \%$ & $21.6 \%$ & $25.8 \%$ & $23.9 \%$ & $25.8 \%$ & $25.5 \%$ & $25.7 \%$ \\
\hline \multirow[t]{2}{*}{ Overweight } & no & $33.1 \%$ & $44.8 \%$ & $39.3 \%$ & $29.2 \%$ & $45.9 \%$ & $38.1 \%$ & $28.5 \%$ & $42.7 \%$ & $36.2 \%$ & $29.5 \%$ & $42.5 \%$ & $36.8 \%$ & $28.8 \%$ & $42.6 \%$ & $36.3 \%$ & $33.3 \%$ & $39.7 \%$ & $36.8 \%$ & $28.5 \%$ & $41.8 \%$ & $35.7 \%$ \\
\hline & yes & $66.9 \%$ & $55.2 \%$ & $60.7 \%$ & $70.8 \%$ & $54.1 \%$ & $61.9 \%$ & $71.5 \%$ & $57.3 \%$ & $63.8 \%$ & $70.5 \%$ & $57.5 \%$ & $63.2 \%$ & $71.2 \%$ & $57.4 \%$ & $63.7 \%$ & $66.7 \%$ & $60.3 \%$ & $63.2 \%$ & $71.5 \%$ & $58.2 \%$ & $64.3 \%$ \\
\hline \multirow[t]{4}{*}{ BMI classification } & under-weight & $0.7 \%$ & $1.1 \%$ & $0.9 \%$ & $0.5 \%$ & $1.3 \%$ & $0.9 \%$ & $0.6 \%$ & $1.1 \%$ & $0.9 \%$ & $0.7 \%$ & $1.1 \%$ & $0.9 \%$ & $0.6 \%$ & $1.1 \%$ & $0.9 \%$ & $0.9 \%$ & $1.2 \%$ & $1.1 \%$ & $0.3 \%$ & $1.0 \%$ & $0.7 \%$ \\
\hline & normal & $32.4 \%$ & $43.7 \%$ & $38.4 \%$ & $28.6 \%$ & $44.6 \%$ & $37.2 \%$ & $28.0 \%$ & $41.6 \%$ & $35.3 \%$ & $28.8 \%$ & $41.4 \%$ & $35.9 \%$ & $28.3 \%$ & $41.5 \%$ & $35.4 \%$ & $32.4 \%$ & $38.4 \%$ & $35.7 \%$ & $28.3 \%$ & $40.7 \%$ & $35.1 \%$ \\
\hline & overweight & $46.6 \%$ & $33.4 \%$ & $39.6 \%$ & $48.1 \%$ & $33.0 \%$ & $40.0 \%$ & $48.7 \%$ & $32.5 \%$ & $40.0 \%$ & $46.5 \%$ & $33.5 \%$ & $39.2 \%$ & $46.8 \%$ & $33.6 \%$ & $39.7 \%$ & $45.1 \%$ & $34.5 \%$ & $39.3 \%$ & $45.6 \%$ & $32.7 \%$ & $38.6 \%$ \\
\hline & obese & $20.3 \%$ & $21.8 \%$ & $21.1 \%$ & $22.7 \%$ & $21.2 \%$ & $21.9 \%$ & $22.8 \%$ & $24.8 \%$ & $23.8 \%$ & $24.0 \%$ & $24.0 \%$ & $24.0 \%$ & $24.3 \%$ & $23.8 \%$ & $24.0 \%$ & $21.6 \%$ & $25.8 \%$ & $23.9 \%$ & $25.8 \%$ & $25.5 \%$ & $25.7 \%$ \\
\hline \multirow[t]{7}{*}{ Years of education } & 8 & $3.2 \%$ & $2.8 \%$ & $3.0 \%$ & $3.2 \%$ & $2.3 \%$ & $2.8 \%$ & $2.6 \%$ & $2.2 \%$ & $2.4 \%$ & $2.4 \%$ & $1.8 \%$ & $2.0 \%$ & $2.4 \%$ & $1.9 \%$ & $2.1 \%$ & $3.9 \%$ & $5.4 \%$ & $4.7 \%$ & $2.2 \%$ & $1.6 \%$ & $1.9 \%$ \\
\hline & 9 & $26.2 \%$ & $26.9 \%$ & $26.6 \%$ & $24.1 \%$ & $21.1 \%$ & $22.5 \%$ & $23.2 \%$ & $23.7 \%$ & $23.4 \%$ & $22.0 \%$ & $22.0 \%$ & $22.0 \%$ & $21.4 \%$ & $21.7 \%$ & $21.6 \%$ & $14.7 \%$ & $15.7 \%$ & $15.3 \%$ & $20.0 \%$ & $19.8 \%$ & $19.9 \%$ \\
\hline & 10 & $32.3 \%$ & $31.2 \%$ & $31.7 \%$ & $30.6 \%$ & $32.4 \%$ & $31.6 \%$ & $31.9 \%$ & $32.1 \%$ & $32.0 \%$ & $32.8 \%$ & $29.7 \%$ & $31.1 \%$ & $32.4 \%$ & $30.9 \%$ & $31.6 \%$ & $25.4 \%$ & $25.0 \%$ & $25.2 \%$ & $30.6 \%$ & $30.8 \%$ & $30.7 \%$ \\
\hline & 11 & $6.7 \%$ & $10.1 \%$ & $8.5 \%$ & $8.2 \%$ & $9.4 \%$ & $8.9 \%$ & $7.8 \%$ & $9.9 \%$ & $9.0 \%$ & $7.5 \%$ & $9.7 \%$ & $8.7 \%$ & $7.2 \%$ & $9.7 \%$ & $8.5 \%$ & $7.8 \%$ & $9.8 \%$ & $8.9 \%$ & $7.6 \%$ & $10.7 \%$ & $9.3 \%$ \\
\hline & 12 & $7.7 \%$ & $10.0 \%$ & $8.9 \%$ & $7.2 \%$ & $11.7 \%$ & $9.6 \%$ & $8.1 \%$ & $11.3 \%$ & $9.8 \%$ & $8.7 \%$ & $11.8 \%$ & $10.4 \%$ & $8.8 \%$ & $11.4 \%$ & $10.2 \%$ & $9.1 \%$ & $11.6 \%$ & $10.5 \%$ & $8.9 \%$ & $11.6 \%$ & $10.3 \%$ \\
\hline & 13 & $8.6 \%$ & $8.3 \%$ & $8.5 \%$ & $10.7 \%$ & $10.6 \%$ & $10.6 \%$ & $10.0 \%$ & $9.7 \%$ & $9.8 \%$ & $10.1 \%$ & $11.2 \%$ & $10.7 \%$ & $10.1 \%$ & $10.5 \%$ & $10.3 \%$ & $16.4 \%$ & $14.8 \%$ & $15.5 \%$ & $11.2 \%$ & $9.1 \%$ & $10.0 \%$ \\
\hline & 15 & $15.2 \%$ & $10.7 \%$ & $12.8 \%$ & $15.9 \%$ & $12.4 \%$ & $14.0 \%$ & $16.4 \%$ & $11.2 \%$ & $13.6 \%$ & $16.5 \%$ & $13.8 \%$ & $15.0 \%$ & $17.7 \%$ & $13.9 \%$ & $15.6 \%$ & $22.7 \%$ & $17.7 \%$ & $20.0 \%$ & $19.6 \%$ & $16.5 \%$ & $17.9 \%$ \\
\hline
\end{tabular}




\section{ANNEX A2}

\section{Regression Analysis Related to Estimates in Figures 2 and 3}

Logistic regression was used to estimate the likelihood of obesity associated with different lengths of time in education for both genders.

\begin{tabular}{|c|c|}
\hline \multirow{2}{*}{ Australia } & Dependant variable: obesity status \\
\hline & Significance \\
\hline \multicolumn{2}{|l|}{ Age } \\
\hline $25-29$ & ref. \\
\hline $30-34$ & $1.287^{\star \star \star}$ \\
\hline $35-39$ & $1.325^{\star * *}$ \\
\hline $40-44$ & $1.450^{\star \star *}$ \\
\hline $45-49$ & $1.717^{\star * *}$ \\
\hline $50-54$ & $1.752^{* * *}$ \\
\hline $55-59$ & $1.604^{\star * *}$ \\
\hline $60-64$ & $1.536^{\star \star *}$ \\
\hline Year of survey & $1.062^{* * *}$ \\
\hline Women & 1.027 \\
\hline \multicolumn{2}{|c|}{ Years of education - Men } \\
\hline 8 & ref. \\
\hline 12 & $0.738^{* * *}$ \\
\hline 14 & $0.568^{* * *}$ \\
\hline \multicolumn{2}{|c|}{ Years of education - Women } \\
\hline 8 & ref. \\
\hline 12 & $0.700 * * *$ \\
\hline 14 & $0.462^{* * *}$ \\
\hline \multicolumn{2}{|c|}{ Socio-economic status } \\
\hline highest & ref. \\
\hline middle-high & $1.157^{\star * *}$ \\
\hline middle & $1.132^{\star \star *}$ \\
\hline middle-low & $1.517^{* * *}$ \\
\hline lowest & $1.381 * * *$ \\
\hline Obs. & 67671 \\
\hline Prob > chi2 & 0.000 \\
\hline Pseudo R2 & 0.032 \\
\hline
\end{tabular}

\begin{tabular}{|c|c|}
\hline \multirow{2}{*}{ Canada } & Dependant variable: obesity status \\
\hline & Significance \\
\hline \multicolumn{2}{|l|}{ Age } \\
\hline $25-29$ & ref. \\
\hline $30-34$ & $1.091^{*}$ \\
\hline $35-39$ & $1.140^{\star * *}$ \\
\hline $40-44$ & $1.180^{\star \star *}$ \\
\hline $45-49$ & $1.391^{\star * *}$ \\
\hline $50-54$ & $1.538^{\star \star \star}$ \\
\hline $55-59$ & $1.543^{* * *}$ \\
\hline $60-64$ & $1.490^{\star * *}$ \\
\hline Year of survey & $1.039^{\star \star \star}$ \\
\hline Women & 0.956 \\
\hline \multicolumn{2}{|c|}{ Years of education - Men } \\
\hline 8 & ref. \\
\hline 12 & $0.848^{* * *}$ \\
\hline 14 & $0.867^{\star *}$ \\
\hline 17 & $0.709^{* * *}$ \\
\hline \multicolumn{2}{|c|}{ Years of education - Women } \\
\hline 8 & ref. \\
\hline 12 & $0.754^{\star * *}$ \\
\hline 14 & 0.896 \\
\hline 17 & $0.599^{* * *}$ \\
\hline \multicolumn{2}{|c|}{ Socio-economic status } \\
\hline highest & ref. \\
\hline middle-high & $1.141^{\star * *}$ \\
\hline middle & $1.136^{\star * *}$ \\
\hline middle-low & $1.151^{* * *}$ \\
\hline lowest & $1.207^{\star \star *}$ \\
\hline Obs. & 219496 \\
\hline Prob > chi2 & 0.000 \\
\hline Pseudo R2 & 0.0124 \\
\hline
\end{tabular}




\begin{tabular}{|c|c|c|c|}
\hline & Dependant variable: obesity status & & Dependant variable: obesity status \\
\hline & Significance & & Significance \\
\hline Age & $1.064^{* \star *}$ & Age & 0.973 \\
\hline Age squared & $0.999 * \star *$ & Age square & 1.000 \\
\hline Year of survey & $1.058^{\star * *}$ & Year of survey & $1.066^{\star * *}$ \\
\hline Women & $1.368^{* \star *}$ & Women & $3.968^{* * *}$ \\
\hline Years of education - Men & & Years of education - Men & \\
\hline 8 & ref. & 6 & ref. \\
\hline 9 & 0.956 & 9 & 1.601 \\
\hline 10 & $0.882^{\star \star}$ & 12 & 1.649 \\
\hline 11 & $0.788^{* * *}$ & 16 & 1.509 \\
\hline 12 & $0.726^{* * *}$ & 17 & 1.909 \\
\hline 13 & $0.706^{\star * *}$ & Years of education - Women & \\
\hline 15 & $0.558^{\star * *}$ & 6 & ref. \\
\hline Years of education - Women & & 9 & 1.007 \\
\hline 8 & ref. & 12 & $0.418^{\star \star \star}$ \\
\hline 9 & $0.792^{\star * *}$ & 16 & $0.195^{\star * *}$ \\
\hline 10 & $0.677^{\star * *}$ & 17 & $1.3 \mathrm{E}-07^{\star \star *}$ \\
\hline 11 & $0.599^{\star \star \star}$ & Socio-economic status & \\
\hline 12 & $0.565^{\star \star \star}$ & highest & ref. \\
\hline 13 & $0.558^{* * *}$ & middle-high & 0.967 \\
\hline 15 & $0.353^{\star * *}$ & middle & 1.001 \\
\hline Socio-economic status & & middle-low & 1.055 \\
\hline highest & ref. & lowest & 1.217 \\
\hline middle-high & $1.235^{\star \star \star}$ & Obs. & 15242 \\
\hline middle & $1.199^{\star \star \star}$ & Prob > chi2 & 0.000 \\
\hline middle-low & $1.347^{\star \star \star}$ & Pseudo R2 & 0.026 \\
\hline lowest & $1.440^{\star \star *}$ & & \\
\hline Obs. & 104143 & & \\
\hline Prob > chi2 & 0.000 & & \\
\hline Pseudo R2 & 0.0266 & & \\
\hline
\end{tabular}


Linear regression was used to estimate BMI level associated with different lengths of time in education for both genders.

\begin{tabular}{|c|c|c|c|}
\hline \multirow{2}{*}{ Australia } & Dependant variable: BMI & \multirow{2}{*}{ Canada } & Dependant variable: BMI \\
\hline & Significance & & Significance \\
\hline Age & & Age & \\
\hline $25-29$ & ref. & $25-29$ & ref. \\
\hline $30-34$ & $0.523^{* * *}$ & $30-34$ & $0.496^{\star * *}$ \\
\hline $35-39$ & $0.695^{* * *}$ & $35-39$ & $0.651^{* * *}$ \\
\hline $40-44$ & $1.006^{* * *}$ & $40-44$ & $0.847^{\star \star \star}$ \\
\hline $45-49$ & $1.422^{* * *}$ & $45-49$ & $1.303^{\star \star \star}$ \\
\hline $50-54$ & $1.575^{* * *}$ & $50-54$ & $1.638^{\star \star \star}$ \\
\hline $55-59$ & $1.575^{* * *}$ & $55-59$ & $1.733^{\star \star \star}$ \\
\hline $60-64$ & $1.454^{\star * *}$ & $60-64$ & $1.552^{\star \star \star}$ \\
\hline Year of survey & $0.123^{* * *}$ & Year of survey & $0.078^{\star \star *}$ \\
\hline Women & $-0.554^{\star \star *}$ & Women & $-0.749^{\star \star \star}$ \\
\hline Years of education - Men & & Years of education - Men & \\
\hline 8 & ref. & 8 & ref. \\
\hline 12 & $-0.351^{* * *}$ & 12 & -0.128 \\
\hline 14 & $-0.883^{* * *}$ & 14 & -0.140 \\
\hline Years of education - Women & & 17 & $-0.506^{\star \star \star}$ \\
\hline 8 & ref. & Years of education - Women & \\
\hline 12 & $0.239^{\star * *}$ & 8 & ref. \\
\hline 14 & $0.867^{* * *}$ & 12 & $-0.801^{\star * *}$ \\
\hline Socio-economic status & & 14 & $-0.725^{\star \star *}$ \\
\hline highest & ref. & 17 & $-1.398^{\star * *}$ \\
\hline middle-high & $0.184^{* * *}$ & Socio-economic status & \\
\hline middle & $0.143^{* *}$ & highest & ref. \\
\hline middle-low & $0.538^{* * *}$ & middle-high & $0.148^{\star * \star}$ \\
\hline lowest & $0.254^{* * *}$ & middle & 0.057 \\
\hline Obs. & 67671 & middle-low & 0.036 \\
\hline Prob $>F$ & 0.000 & lowest & -0.091 \\
\hline \multirow[t]{3}{*}{ Pseudo R2 } & 0.0709 & Obs. & 219496 \\
\hline & & Prob $>F$ & 0.000 \\
\hline & & Pseudo R2 & 0.0514 \\
\hline
\end{tabular}




\begin{tabular}{|c|c|c|c|}
\hline & Dependant variable: BMI & & Dependant variable: BMI \\
\hline & Significance & & Significance \\
\hline Age & $0.183^{\star * *}$ & Age & $0.223^{\star * *}$ \\
\hline Age squared & $-0.001^{* * *}$ & Age square & $-0.002^{\star * *}$ \\
\hline Year of survey & $0.120^{\star \star *}$ & Year of survey & $0.065^{\star \star \star}$ \\
\hline Women & $0.503^{* \star *}$ & Women & $1.300^{\star \star \star}$ \\
\hline Years of education - Men & & Years of education - Men & \\
\hline 8 & ref. & 6 & ref. \\
\hline 9 & 0.027 & 9 & $0.487^{\star \star \star}$ \\
\hline 10 & -0.071 & 12 & $0.739^{\star * \star}$ \\
\hline 11 & $-0.312^{\star \star}$ & 16 & $0.922^{\star \star \star}$ \\
\hline 12 & $-0.390^{\star * *}$ & 17 & $1.379^{\star * *}$ \\
\hline 13 & $-0.569^{\star * *}$ & Years of education - Women & \\
\hline 15 & $-0.948^{\star * *}$ & 6 & ref. \\
\hline Years of education - Women & & 9 & 0.042 \\
\hline 8 & ref. & 12 & $-1.167^{\star \star *}$ \\
\hline 9 & $-0.603^{\star \star *}$ & 16 & $-2.223^{\star \star *}$ \\
\hline 10 & $-1.028^{* * *}$ & 17 & $-2.584^{* * *}$ \\
\hline 11 & $-1.401^{* * *}$ & Socio-economic status & \\
\hline 12 & $-1.598^{\star \star \star}$ & highest & ref. \\
\hline 13 & $-1.622^{\star \star *}$ & middle-high & $-0.184^{\star *}$ \\
\hline 15 & $-2.647^{\star * *}$ & middle & -0.104 \\
\hline Socio-economic status & & middle-low & -0.124 \\
\hline highest & ref. & lowest & $-0.294^{\star \star \star}$ \\
\hline middle-high & $0.332^{\star \star *}$ & Obs. & 15704 \\
\hline middle & $0.196^{\star \star *}$ & Prob $>F$ & 0.000 \\
\hline middle-low & $0.434^{\star \star *}$ & Pseudo R2 & 0.0806 \\
\hline lowest & $0.467^{\star \star *}$ & & \\
\hline Obs. & 104143 & & \\
\hline Prob $>F$ & 0.000 & & \\
\hline Pseudo R2 & 0.0503 & & \\
\hline
\end{tabular}




\section{ANNEX A3}

\section{Regression Analysis Related to Estimates in Figures 4 to 6}

Logistic regression was used to estimate the likelihood of obesity associated with different lengths of time in education for both genders and by ethnicity/minority status.

Table A3.1. Australia

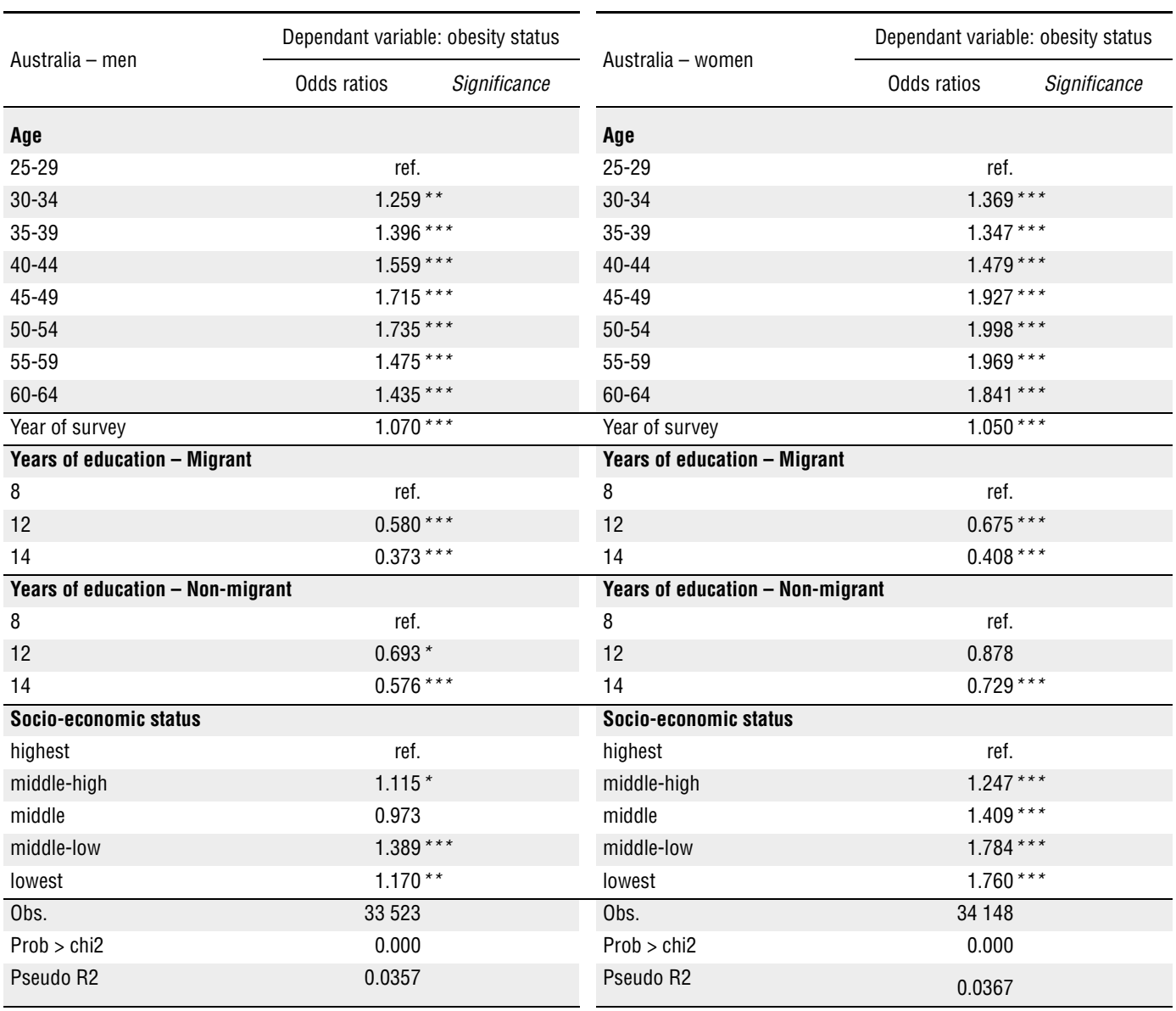


Table A3.2. Canada

\begin{tabular}{|c|c|c|c|}
\hline \multirow{2}{*}{ Canada - men } & Dependant variable: obesity status & \multirow{2}{*}{ Canada - women } & Dependant variable: obesity status \\
\hline & Significance & & Significance \\
\hline \multicolumn{2}{|l|}{ Age } & \multicolumn{2}{|l|}{ Age } \\
\hline $25-29$ & ref. & $25-29$ & ref. \\
\hline $30-34$ & $1.222^{* * *}$ & $30-34$ & $1.193^{* * *}$ \\
\hline $35-39$ & $1.203^{* * *}$ & $35-39$ & $1.160 * * *$ \\
\hline $40-44$ & $1.197^{* * *}$ & $40-44$ & $1.210 * * *$ \\
\hline $45-49$ & $1.366^{* * *}$ & $45-49$ & $1.441^{* * *}$ \\
\hline $50-54$ & $1.471 * * *$ & $50-54$ & $1.689^{* * *}$ \\
\hline $55-59$ & $1.475^{\star \star *}$ & $55-59$ & $1.646^{* * *}$ \\
\hline $60-64$ & $1.323^{* * *}$ & $60-64$ & $1.474^{* * *}$ \\
\hline Year of survey & $1.030 * * *$ & Year of survey & $1.053^{* \star *}$ \\
\hline \multicolumn{2}{|c|}{ Years of education - Non-minority } & \multicolumn{2}{|c|}{ Years of education - Non-minority } \\
\hline 8 & ref. & 8 & ref. \\
\hline 12 & $0.880 * * *$ & 12 & $0.823^{* * *}$ \\
\hline 14 & $0.869 * * *$ & 14 & $0.843^{* * *}$ \\
\hline 17 & $0.735^{\star * *}$ & 17 & $0.739 * * *$ \\
\hline Years of educa & & Years of educatio & \\
\hline 8 & ref. & 8 & ref. \\
\hline 12 & $0.639 * * *$ & 12 & $0.529 * * *$ \\
\hline 14 & $0.761 * * *$ & 14 & 0.926 \\
\hline 17 & $0.467^{* * *}$ & 17 & $0.549 * * *$ \\
\hline Socio-economi & & Socio-economic s & \\
\hline highest & ref. & highest & ref. \\
\hline middle-high & 0.988 & middle-high & $1.323^{\star * *}$ \\
\hline middle & 0.941 ** & middle & $1.554^{* * *}$ \\
\hline middle-low & 0.944 & middle-low & $1.825^{* * *}$ \\
\hline lowest & $0.875^{* * *}$ & lowest & $1.821^{* * *}$ \\
\hline Obs. & 101113 & Obs. & 106698 \\
\hline Prob > chi2 & 0.000 & Prob > chi2 & 0.000 \\
\hline Pseudo R2 & 0.0075 & Pseudo R2 & 0.0179 \\
\hline
\end{tabular}


Table A3.3. England

\begin{tabular}{|c|c|c|c|}
\hline & Dependant variable: obesity status & & Dependant variable: obesity status \\
\hline & Significance & & Significance \\
\hline Age & $1.089^{* * *}$ & Age & $1.042^{\star * *}$ \\
\hline Age squared & $0.999 * * *$ & Age squared & $1.000^{* \star *}$ \\
\hline Year of survey & $1.067^{\star * *}$ & Year of survey & $1.050^{* * *}$ \\
\hline Years of education - White & & Years of education - White & \\
\hline 8 & ref. & 8 & ref. \\
\hline 9 & $0.869 * *$ & 9 & $0.886^{* *}$ \\
\hline 10 & $0.781^{* * *}$ & 10 & $0.774^{\star \star *}$ \\
\hline 11 & $0.701^{* * *}$ & 11 & $0.696^{\star * *}$ \\
\hline 12 & $0.626^{* \star *}$ & 12 & $0.656^{* * *}$ \\
\hline 13 & $0.640 * * *$ & 13 & $0.615^{* * *}$ \\
\hline 15 & $0.471^{* * *}$ & 15 & $0.414^{* * *}$ \\
\hline Years of education - Black & & Years of education - Black & \\
\hline 8 & ref. & 8 & ref. \\
\hline 9 & $0.517^{* * *}$ & 9 & $1.631^{\star * *}$ \\
\hline 10 & $0.618^{* * *}$ & 10 & $1.650^{* * *}$ \\
\hline 11 & $0.537^{\star *}$ & 11 & $1.582^{\star * *}$ \\
\hline 12 & 0.664 & 12 & $1.396^{* *}$ \\
\hline 13 & $0.677^{\star *}$ & 13 & $1.862^{* * *}$ \\
\hline 15 & $0.634^{* *}$ & 15 & 0.984 \\
\hline Years of education - Asian & & Years of education - Asian & \\
\hline 8 & ref. & 8 & ref. \\
\hline 9 & $0.517^{\star \star \star *}$ & 9 & 1.631 \\
\hline 10 & $1.169^{\star \star \star}$ & 10 & 1.142 \\
\hline 11 & $0.970 * * *$ & 11 & $0.704^{* \star *}$ \\
\hline 12 & $1.153^{\star * *}$ & 12 & $0.831^{* * *}$ \\
\hline 13 & $0.826^{\star \star \star}$ & 13 & $0.762^{* \star *}$ \\
\hline 15 & $0.762^{\star \star \star *}$ & 15 & $0.615^{* * *}$ \\
\hline Socio-economic status & & Socio-economic status & \\
\hline highest & ref. & highest & ref. \\
\hline middle-high & $1.220^{* \star *}$ & middle-high & $1.378^{* * *}$ \\
\hline middle & $1.185^{* * *}$ & middle & $1.347^{* * *}$ \\
\hline middle-low & $1.135^{* *}$ & middle-low & $1.682^{* * *}$ \\
\hline lowest & 1.022 & lowest & $1.930 * * *$ \\
\hline Obs. & 48558 & Obs. & 55585 \\
\hline Prob > chi2 & 0.000 & Prob > chi2 & 0.000 \\
\hline Pseudo R2 & 0.0261 & Pseudo R2 & 0.0312 \\
\hline
\end{tabular}




\section{ANNEX A4}

\section{Multilevel models}

This methodological annex gives a description of the multilevel model.

Let $y_{i}$ be the value of the response variable $Y$ for the individual $i$, and $X_{1}$ an independent covariate in a simple univariate model, the single-level regression equation for the individual $i$ is given by:

$$
y_{i}=\beta_{0}+\beta_{1} x_{1 i}+e_{i}
$$

where $\beta_{0}$ is the intercept, $\beta_{1}$ the regression coefficient and the individual-level residuals $e_{\mathrm{i}}$ with $e_{\mathrm{i}} \sim \mathrm{N}\left(0, \sigma_{\mathrm{e}}{ }^{2}\right)$.

In order to evaluate the significance of a higher order aggregation of individuals in $n$ groups on the single values $y_{i}$, the regression model in (1) can be written as:

$$
y_{i j}=\beta_{0 j}+\beta_{1 j} x_{1 i j}+e_{i j}
$$

where $j=1, \ldots, n$ refers to the level-2 units (groups) and $i=1, \ldots, N$, to the level- 1 units (individuals).

The model in equation (2) is called random intercept model when the intercept $\beta_{0}$ in (1) becomes a random variable depending on the group $j$, that is:

$$
\beta_{0 j}+\beta_{0}+u_{0 j}
$$

with $u_{0 j} \sim N\left(0, \sigma_{u 0}{ }^{2}\right)$ as group-level residuals. When considering also the regression coefficient $\beta_{1}$ as a random variable such as:

$$
\beta_{1 j}+\beta_{1}+u_{1 j}
$$

with $u_{1 j} \sim N\left(0, \sigma_{u 1}{ }^{2}\right)$ and $\operatorname{cov}\left(u_{0 j}, u_{1 j}\right)=\sigma_{u 01}$, the model in equation (2) is called random coefficient model and can be written in the form:

$$
y_{i j}=\beta_{0}+\beta_{1} x_{1 i j}+\left(u_{0 j}+u_{1 j} x_{1 i j}+e_{i j}\right)
$$

In equation (5) the response variable $y_{i j}$ has been expressed as the sum of a fixed part and a random part within the brackets, where the covariate $x_{1 \mathrm{ij}}$ in the random part of the model is usually substituted by $z_{1 i j}$ to make the distinction with the covariates in the fixed part. In model (5) both intercept and regression coefficients vary from group to group, so as to explain the effect of the group's aggregation on the Y variable. The individual-level residuals $e_{i j}$ are assumed to be independent from the group-level residuals $u_{0 j}$ and $u_{1 j}$.

The intra level-2 unit correlation in random intercept models is given by:

$$
\rho=\frac{\sigma_{u 0}^{2}}{\sigma_{u 0}^{2}+\sigma_{e}^{2}}
$$


and measures the proportion of the total variance which is between-groups. The same correlation index in case of random coefficient models equals:

$$
\rho=\frac{\sigma_{u 0}^{2}+2 \sigma_{01} z_{1 i j}+\sigma_{u 1}^{2} z_{1 i j}^{2}}{\sigma_{u 0}^{2}+2 \sigma_{01} z_{1 i j}+\sigma_{u 1}^{2} z_{1 i j}^{2}+\sigma_{e}^{2}}
$$

The existence of a non-zero intra-group correlation indicates that traditional estimation procedures used in multiple regressions, such as ordinary least squares, are not correct. For this reason, estimation methods for multilevel models include generalised least square techniques (Goldstein, 1986), Fisher scoring algorithm (Longford, 1987) or the expectation-maximisation algorithm (Raudenbush and Bryk, 1986). The simple 2-level random coefficient model in (5) can be further extended by introducing more explanatory variables at either the individual or the group levels. Moreover, the number of nested levels can be increased when considering more aggregation stages.

In this case $\mathrm{y}_{\mathrm{ij}}$ is a discrete response, the model is a hierarchical logistic model and the random intercept model is:

$$
y_{i j}=\beta_{0}+\beta_{1} x_{1 i}+\left(u_{0 j}+e_{i j}\right)
$$

with $\mathrm{e}_{\mathrm{ij}}$ having logistic distribution and the individual-level variance $\sigma^{2}{ }_{\mathrm{e}}$ is equal to $\pi^{2} / 3$. So, the intra-class correlation is (with $\sigma^{2}$ uo the group-level variance):

$$
\rho=\frac{\sigma_{u 0}^{2}}{\sigma_{u 0}^{2}+\frac{\pi^{2}}{3}}
$$

